\author{
Board of Governors of the Federal Reserve System \\ International Finance Discussion Papers
}

Number $995 \mathrm{r}$

December 2012

\title{
Offshore Production and Business Cycle Dynamics with Heterogeneous Firms
}

\author{
Andrei Zlate
}

NOTE: International Finance Discussion Papers are preliminary materials circulated to stimulate discussion and critical comment. References to International Finance Discussion Papers (other than an acknowledgment that the writer has had access to unpublished material) should be cleared with the author or authors. Recent IFDPs are available on the Web at www.federalreserve.gov/pubs/ifdp/. This paper can be downloaded without charge from the Social Science Research Network electronic library at www.ssrn.com. 


\title{
Offshore Production and Business Cycle Dynamics \\ with Heterogeneous Firms*
}

\author{
Andrei Zlate** \\ Federal Reserve Board
}

December 2012

\begin{abstract}
Cross-country variation in production costs encourages firms to relocate production to other countries, a process known as offshoring through vertical foreign direct investment (FDI). To examine the effect of offshoring through vertical FDI on the international transmission of business cycles, I propose a model that distinguishes between fluctuations in the number of offshoring firms (the extensive margin) and in the value added per offshoring firm (the intensive margin) as separate transmission mechanisms. In the model, firms face a sunk cost to enter the domestic market, and an additional fixed cost to produce offshore. The offshoring decision depends on the firm-specific productivity and on fluctuations in the relative cost of effective labor. The model replicates the procyclical pattern of offshoring, as well as the dynamics along its extensive and intensive margins, which I document using data from U.S. manufacturing and Mexico's maquiladora sector. In addition, offshoring enhances the comovement of output across countries, in line with existing empirical evidence. The result is closely related to the dynamics of offshoring along its extensive and intensive margins.
\end{abstract}

JEL classification: F23, F41

Keywords: offshore production; extensive margin; heterogeneous firms; firm entry; business cycle dynamics; terms of labor.

\footnotetext{
* I thank Fabio Ghironi, James Anderson and Susanto Basu for their guidance, as well as George Alessandria, Richard Arnott, David Arseneau, Marianne Baxter, Michele Cavallo, Matteo Iacoviello, Federico Mandelman, Fernando Parro, Joel Rodrigue, Vitaliy Strohush and Linda Tesar for helpful suggestions, and Quoctrung Bui for his excellent research assistance. Participants at the 2012 Dynare Conference at the Swiss National Bank, the 2012 Midwest Macro Meetings, the 2011 Asian Meeting of the Econometric Society, the 2010 Winter Meeting of the Econometric Society, the 2009 SCIEA meeting of the Federal Reserve, the Federal Reserve Board, the 2009 International Economics and Finance Society/ASSA meeting, and the Green Line Macro Workshop at Boston College/Boston University provided helpful comments.

** Contact email: Andrei.Zlate@,frb.gov, phone: (202) 452-3542. The author is a staff economist in the Division of International Finance, Board of Governors of the Federal Reserve System, $20^{\text {th }}$ and C Street NW, Washington, D.C. 20551 U.S.A. The views in this paper are solely the responsibility of the author and should not be interpreted as reflecting the views of the Board of Governors of the Federal Reserve System or of any other person associated with the Federal Reserve System.
} 


\section{Introduction}

Firms often establish production affiliates at foreign locations to benefit from relatively lower production costs, a process known in the international economics literature as offshoring through vertical foreign direct investment (FDI). ${ }^{1}$ Unlike offshoring through horizontal FDI, under which firms relocate production abroad to gain access to the local market, the type of offshoring that I model is motivated by cross-country differences in the cost of effective labor, as foreign affiliates produce goods that are shipped for consumption back to their home country. ${ }^{2}$ The number of offshoring firms (the extensive margin) and the value added per offshoring firm (the intensive margin) fluctuate over the business cycle, and thus affect output, prices and wages in the home and the foreign economies. In addition, since the offshore production is part of the aggregate output of the foreign economy but is affected by demand from home, offshoring through vertical FDI has potential implications for the comovement of output between the economies involved.

To motivate the model of offshoring proposed by this paper, I document empirically the business cycle fluctuations of offshoring through vertical FDI, with particular focus on its extensive and intensive margins, using time series data on U.S. manufacturing and Mexico's maquiladora sector as an example. ${ }^{3}$ The data show that both the total value added offshore and the number of maquiladora plants (a proxy for the extensive margin) are procyclical with the U.S. manufacturing output (see Figure 3, panels 1 and 3), and that the offshoring sector comoves more closely with U.S. manufacturing than does Mexico's total manufacturing output. In addition,

\footnotetext{
1 "Offshoring" refers to the activity of firms that relocate certain stages of production to foreign countries. In contrast, "outsourcing" refers to firms that purchase intermediates from unaffiliated suppliers, located either at home or abroad, rather than producing them in house (see Helpman, 2006).

${ }^{2}$ Helpman, Melitz and Yeaple (2004) model exports and horizontal FDI as alternative internationalization strategies for multinational firms. Contessi (2010) analyzes this trade-off in a business cycle framework. Also see Helpman (1984).

${ }^{3}$ The maquiladora sector in Mexico consists of manufacturing plants that import intermediate goods, process them, and export the resulting output, thus accomodating the offshoring activities of U.S. manufacturing firms.
} 
the offshoring dynamics differ across the total value added and the number of plants: The total value added in Mexico comoves contemporaneously with U.S. manufacturing, whereas the number of maquiladora plants lags the expansions and contractions in U.S. manufacturing by about one year. This pattern highlights the gradual adjustment of the extensive margin of offshoring in response to shocks in the home economy, and thus its role in the propagation of shocks across countries.

This evidence adds to existing empirical studies showing that fluctuations in the extensive margin of offshoring have substantial macroeconomic effects. Bergin, Feenstra and Hanson (2009) find that the extensive margin accounts for about one-third to one-half of the adjustment of Mexico's maquiladora employment. In addition, Kurz (2006) shows that, although offshoring is undertaken by only a small fraction of U.S. manufacturing firms, the offshoring firms are larger and more productive than their domestically-oriented counterparts. This finding helps explain why the offshoring activities of just a subset of firms can have important macroeconomic implications for the economies involved. The combined empirical evidence suggests that modelling the extensive margin of offshoring in a framework with heterogeneous firms can provide new insights on the channels and the timing at which shocks are transmitted across economies.

Motivated by these observations, I examine the business cycle dynamics of offshoring through vertical FDI, and study the effect of offshoring on aggregate dynamics and the macroeconomic interdependence across countries. For this purpose, I build a two-country (i.e. North and South), dynamic stochastic general equilibrium model that rationalizes the firms' decision to relocate production offshore. The key model ingredients are endogenous firm entry in the home country, firm heterogeneity in labor productivity, and endogenous offshoring. Firm entry in 
the home country is subject to a sunk cost reflecting headquarter activities at home. Following entry in the North, each firm can use either domestic or foreign labor in producing for the home market. The use of foreign labor involves the establishment of an offshore plant, and is subject to fixed and trade costs every period. ${ }^{4}$ Since firms are heterogeneous in productivity, the decision to produce offshore is firm-specific; despite the lower cost of effective labor abroad (defined as the real wage normalized by aggregate productivity), only the more productive firms can afford the fixed and trade costs associated with offshoring. The cross-country asymmetry in the cost of effective labor also implies that offshoring takes place one-way; only some of the Northern firms have an incentive to produce offshore, whereas all Southern firms produce at home.

The results are as follows. First, the model generates a procyclical pattern of offshoring, and dynamics along its extensive and intensive margins that are consistent with the data from U.S. manufacturing and Mexico's maquiladora sector. In the model, the fraction of offshoring firms every period depends on the fluctuations in the relative cost of effective labor across countries. A positive shock to aggregate productivity in the North encourages domestic firm entry, and causes the home wage to persist above aggregate productivity, as labor demand increases to accommodate firm entry requirements. Importantly, due to firm entry in the North, the increase in the cost of effective labor in is gradual, which in turn triggers a gradual increase in the number of offshoring firms (the extensive margin), like in the data. Second, as a result of these dynamics, offshoring is highly correlated with home output, and a greater prevalence of offshoring enhances the comovement of output across countries. The increase in output in the North (generated by a country-specific shock to aggregate productivity) and

\footnotetext{
${ }^{4}$ This paper assumes a one-to-one correspondence between a firm, a variety, and an offshore plant.
} 
also in the South (caused by the increase in Northern demand for offshored varieties and the relocation of production to the South) enhance output comovement. The result is consistent with the empirical evidence in Burstein, Kurz, and Tesar (henceforth BKT, 2008), who show that country pairs with larger shares of offshoring-related trade in bilateral trade exhibit larger correlations of manufacturing output.

This paper adds to the international macroeconomics literature on offshoring, which does not fully capture the business cycle dynamics of offshoring along its extensive margin. BKT propose a model in which production sharing enhances the comovement of output, but in which the location of production is fixed (thus abstracting from the extensive margin), and comovement results from a very low elasticity of substitution between the country-specific goods in the vertically-integrated sector. In the model proposed here, offshoring enhances the comovement of output through a mechanism that is different from BKT: The elasticity of substitution between varieties produced domestically and offshore is set at relatively high level that is consistent with firm-level studies, and hence the intensive margin plays a smaller role in comovement. Instead, output comovement is closely linked to procyclical firm entry in the North, the appreciation of the terms of labor, and in turn the adjustment of the offshoring along both its extensive and intensive margins. Arkolakis and Ramanarayanan (2009) build a model with two stages of production, in which heterogeneity in production efficiency gives rise to vertical specialization across countries, and output comovement is related to the transfer of productivity gains through the imports of cheaper intermediate goods. In comparison, my model examines offshoring in a one-stage production setting, in which firm heterogeneity gives rise to intertemporal dynamics of offshoring along its two margins that are consistent with the data, which in turn generate procyclical offshoring and output comovement. Bergin, Feenstra and Hanson (BFH, 2011) 
study the importance of offshoring in amplifying the transmission of shocks across countries, in a model in which the number of offshoring firms adjusts instantly, rather than gradually over time as in the data, in response to simultaneous shocks in the home and foreign economies. However, while BFH study the impact of offshoring on output volatility, this paper focuses on output comovement and the intertemporal dynamics of offshoring. ${ }^{5}$ More generally, this paper is related to a growing body of macroeconomic literature that focuses on endogenous firm entry and adjustments along the extensive margin of exports (but not of offshoring). For example, Ghironi and Melitz (2005) study the export decision of firms in the presence of fixed exporting costs, in a framework with endogenous firm entry and heterogeneous firms. ${ }^{6}$ Alessandria and Choi (2007) analyze the extensive margin of exports in a model with sunk exporting costs and fixed continuation costs that explains the "exporter hysteresis" behavior. ${ }^{7}$

The model implications are robust in the presence of endogenous labor supply and physical capital accumulation. With endogenous labor supply, the response of offshoring is similar, but stronger than in the baseline model. Following a positive shock to productivity the North, firm entry - and hence labor demand - increases by more than in the baseline model, as new firms are attracted by the increased supply of more productive labor, and the larger market size arising from higher labor income. In turn, the terms of labor appreciate by more in the quarters after the shock, thus enhancing the firms' incentive to relocate production offshore. The addition of physical capital dampens but does not reverse the dynamics of offshoring. Since investment

\footnotetext{
${ }^{5}$ Also see Arseneau and Leduc (2011), who study offshoring as an outside option in wage negotiations by multinational firms, and highlight its effect on wages and labor market allocations in a two-country labor search model. In addition, Ottaviano, Peri and Wright (2012) analyze the impact of a reduction in the costs of offshoring and immigration on employment, in a multi-sector model with a continuum of tasks in each sector, and heterogeneity in the immigrant workers' productivity and in the offshoring costs across tasks.

${ }^{6}$ See Fattal Jaef and Lopez (2012), who examine the implications of firm entry and firm exporting costs like in Ghironi and Melitz (2005) in the presence of physical capital and endogenous labor supply. Also see Farhat (2009) for a similar study under various assumptions for labor supply.

7 "Exporter hysteresis" refers to the behavior of firms that continue to serve the foreign market even after a real exchange rate appreciation reduces their export competitiveness.
} 
in physical capital and firm entry are substitutes, a positive shock to aggregate productivity in the North leads to slower firm entry, and therefore to a slower increase in the marginal cost of production relative to the South. However, firm entry and production costs are still procyclical, resulting in a gradual increase in the number of offshoring firms and the total value added offshore.

The rest of the paper is organized as follows: Section 2 introduces the baseline model. Section 3 translates the model with heterogeneous firms into an equivalent framework with two representative firms that produce domestically and offshore, and describes the baseline model calibration. Section 4 presents the alternative models with elastic labor supply and physical capital. Section 5 presents the results, including the business cycle dynamics of offshoring, the dynamics of its two margins, and the relation between offshoring and output comovement. Section 6 concludes with a summary and possible extensions of the model.

\section{Model of Offshoring with Heterogeneous Firms}

The model consists of two economies, North and South. Each economy includes one representative household and a continuum of firms that are monopolistically competitive and heterogeneous in labor productivity. Each firm produces a different variety of goods, and the Northern firms have the option to produce either domestically or offshore in order to serve their home market. This section describes the problem of the representative household and the firms in the North under financial autarky, while the Appendix presents the model version with international trade in bonds. ${ }^{8}$ Agents in the South face a similar problem, except for that all

\footnotetext{
${ }^{8}$ I use "financial autaky" to refer to the absence of international bond or stock trading. However, the characterization of offshoring as a type of foreign direct investment, with the Northern household investing in firms that may produce abroad, could be considered a form of financial integration.
} 
Southern firms produce domestically due to the steady-state asymmetry in the marginal cost of production across countries, which is higher in the North. Variables for the Southern economy are marked with a star superscript.

\subsection{Household's Problem}

The representative household in the North maximizes the expected lifetime utility subject to a budget constraint: $\max _{\left\{B_{t+1}, x_{t+1}\right\}}\left[E_{t} \sum_{s=t}^{\infty} \beta^{s-t} \frac{C_{s}^{1-\gamma}}{1-\gamma}\right]$, where $\beta \in(0,1)$ is the subjective discount factor, $C_{t}$ is aggregate consumption, and $\gamma>0$ is the inverse of the inter-temporal elasticity of substitution. The budget constraint is:

$$
\left(\widetilde{v}_{t}+\widetilde{d}_{t}\right) N_{t} x_{t}+\left(1+r_{t}\right) B_{t}+w_{t} L \geqslant \widetilde{v}_{t}\left(N_{t}+N_{E, t}\right) x_{t+1}+B_{t+1}+C_{t} .
$$

The representative household starts every period with share holdings $x_{t}$ in a mutual fund of $N_{t}$ firms whose average market value is $\widetilde{v}_{t}$, as in Ghironi and Melitz (2005), and also with real bond holdings $B_{t} \cdot{ }^{9}$ It receives dividends equal to the average firm profit $\widetilde{d}_{t}$ in proportion with the number of firms $N_{t}$. It also receives interest $r_{t} B_{t}$ on bond holdings, and the real wage $w_{t}$ for the amount of labor $L \equiv 1$ supplied inelastically. (The alternative models in Section 4 allow for endogenous labor supply, and also for households to invest in physical capital, which is used in production by firms).

The representative household purchases two types of assets every period. First, it purchases $x_{t+1}$ shares in a mutual fund of Northern firms that includes: (i) a number of $N_{t}$ incumbent

\footnotetext{
${ }^{9}$ In the baseline model, in which stocks and bonds are not traded across countries, the equilibrium conditions for stock and bond holdings are $x_{t}=x_{t+1}=1$ and $B_{t}=B_{t+1}=0$. Bond holdings play a role in the model version with financial integration, described in the Appendix, in which the representative household buys riskfree, country-specific bonds in the presence of quadratic adjustment costs for bond holdings.
} 
firms that produce either domestically or offshore at time $t$, and (ii) a number of $N_{E, t}$ new firms that enter the market in period $t$. On average, each firm is worth its market value $\widetilde{v}_{t}$, which is equal to the net present value of the expected stream of future profits. (The mechanisms driving the number of incumbent firms, the number of new entrants and the firms' market value are discussed in Section 2.2 below.) The household also purchases the risk-free bond $B_{t+1}$ denominated in units of the Northern consumption basket. Finally, the household purchases the consumption basket $C_{t}$ :

$$
C_{t}=[\underbrace{\int_{z_{\min }}^{z_{V, t}} y_{D, t}(\omega)^{\frac{\theta-1}{\theta}} d \omega}_{\omega \in \Omega_{t}^{N N}}+\underbrace{\int_{z_{V, t}}^{\infty} y_{V, t}(\omega)^{\frac{\theta-1}{\theta}} d \omega}_{\omega \in \Omega_{t}^{N S}}+\underbrace{\int_{z_{H, t}^{*}}^{\infty} y_{H, t}^{*}(\omega)^{\frac{\theta-1}{\theta}} d \omega}_{\omega \in \Omega_{t}^{S S}}]^{\frac{\theta}{\theta-1}},
$$

which includes varieties produced by the Northern firms either domestically $\left(\omega \in \Omega_{t}^{N N}\right.$ ) or offshore $\left(\omega \in \Omega_{t}^{N S}\right)$, and also varieties produced by the Southern exporting firms ( $\omega \in \Omega_{t}^{S S}$ ); $\theta>1$ is the symmetric elasticity of substitution across varieties. As described in Sections 2.2 and 2.3 below, $\left[z_{\min }, \infty\right)$ is the support interval for the idiosyncratic productivity of Northern firms, and $z_{V, t}$ is the endogenous productivity cutoff above which firms produce offshore for the home market. ${ }^{10}$ Since the number of firms is time-variant and firms re-optimize their offshoring and exporting strategies every period, the composition of the consumption basket changes over time.

I use the home consumption basket $C_{t}$ as the numeraire good, so that the price index in the North is $1=\left[\int \rho_{t}(\omega)^{1-\theta} d \omega\right]^{\frac{1}{1-\theta}}$, where $\omega \in \Omega_{t}^{N N} \cup \Omega_{t}^{N S} \cup \Omega_{t}^{S S}$, and $\rho_{t}(\omega)$ is the real price

\footnotetext{
${ }^{10}$ As explained later, only the more productive firms, whose idiosyncratic productivity is larger than the cutoff levels $z_{V, t}$ and $z_{H, t}$, engage in offshoring and exporting, respectively. In the South, $\left[z_{\min }^{*}, \infty\right)$ is the support interval for the idiosyncratic productivity of Southern firms, and $z_{H, t}^{*}$ is the endogenous productivity cutoff of Southern exporters.
} 
of each variety expressed in units of the North consumption basket. The first-order conditions generate the Euler equations for bonds and stocks:

$$
\begin{aligned}
C_{t}^{-\gamma} & =\beta\left(1+r_{t+1}\right) E_{t}\left[C_{t+1}^{-\gamma}\right], \\
\widetilde{v}_{t} & =\beta(1-\delta) E_{t}\left[\left(\frac{C_{t+1}}{C_{t}}\right)^{-\gamma}\left(\widetilde{d}_{t+1}+\widetilde{v}_{t+1}\right)\right],
\end{aligned}
$$

where $\delta$ is the exogenous rate of firm exit every period, described next.

\section{$2.2 \quad$ Firm Entry and Exit}

Firm entry (i.e. the creation of new firms in the home economy) takes place every period in both the North and the South, as in Ghironi and Melitz (2005). In the North, firm entry requires a sunk entry cost equal to $f_{E}$ units of Northern effective labor, which reflects headquarter activities in the home country (such as research and development). ${ }^{11}$ After paying the sunk entry cost, each firm is randomly assigned an idiosyncratic labor productivity factor $z$ that is drawn independently from a common distribution $G(z)$ with support over the interval $\left[z_{\min }, \infty\right)$, and which the firm keeps for the entire duration of its life.

The $N_{E, t}$ firms created at time $t$ do not produce until $t+1$. Also, irrespective of their idiosyncratic productivity, all firms - including the new entrants - are subject to a random exit shock that occurs with probability $\delta$ at the end of every period. Thus, the law of motion for the number of producing firms is: $N_{t+1}=(1-\delta)\left(N_{t}+N_{E, t}\right)$.

The potential entrant firms anticipate their expected post-entry value $\widetilde{v_{t}}$, which depends on the expected stream of future profits $\widetilde{d}_{t}$, the stochastic discount factor, and the exogenous

\footnotetext{
${ }^{11}$ The sunk entry cost is equivalent to $f_{E} w_{t} / Z_{t}$ units of the Northern consumption basket.
} 
probability $\delta$ of exit every period. The forward iteration of the Euler equation for stocks (4) generates the following expression for the expected post-entry value of the average firm:

$$
\widetilde{v_{t}}=E_{t}\left\{\sum_{s=t+1}^{\infty}[\beta(1-\delta)]^{s-t}\left(\frac{C_{s}}{C_{t}}\right)^{-\gamma} \widetilde{d}_{s}\right\} .
$$

Thus, every period, the unbounded pool of potential entrant firms face a trade-off between the sunk entry cost and the expected stream of future monopolistic profits. In equilibrium, firm entry takes place until the expected value of the average firm is equal to the sunk entry cost expressed in units of the Northern consumption basket: $\widetilde{v}_{t}=f_{E} \frac{w_{t}}{Z_{t}}$.

\subsection{Markets and Production Strategies}

Every period $t$, the active firms $N_{t}$ choose the destination market(s) that they serve and the location of production every period, as follows:

1. All firms serve their home market. For this purpose, the Northern firms can produce either at home or offshore. Offshoring offers the advantage of a lower production cost, but is subject to fixed and trade costs every period. Importantly, given that this paper focuses on offshoring through vertical FDI, the firms' choice between producing at home or offshore concerns the output intended for the home market only, and is not guided by access to the foreign market.

2. A subset of firms from each economy also serve the foreign market. Since the channel of offshoring through horizontal FDI is beyond the scope of this paper, the firms serving the foreign market use exclusively home labor in production, and export their varieties 
subject to a per-period fixed cost as in Ghironi and Melitz (2005). ${ }^{12}$

Each of these two problems - the offshoring decision of firms serving their home market, as well as the exporting decision of firms serving the foreign market - are described below.

\subsubsection{Firms Serving the Domestic Market: Domestic vs. Offshore Production}

This section illustrates the mechanisms of domestic and offshore production as alternative choices for the Northern firms that produce for the home market. Every period, the firm with labor productivity $z$ must choose one of the two possible production strategies:

(a) Produce domestically: $y_{D, t}(z)=Z_{t} z l_{t}$, with output as a function of the aggregate productivity in the North $Z_{t}$, the firm-specific labor productivity $z$, and domestic labor $l_{t}$.

(b) Alternatively, produce offshore: $y_{V, t}(z)=Z_{t}^{*} z l_{t}^{*}$. Thus, the Northern firm producing offshore uses Southern labor $l_{t}^{*}$ and becomes subject to the aggregate productivity of the South $Z^{*}$, but is able to carry its own idiosyncratic labor productivity $z$ abroad.

Under monopolistic competition, the firm with idiosyncratic productivity $z$ solves the profitmaximization problem for the alternative scenarios of domestic and offshore production:

$$
\begin{aligned}
& \max _{\left\{\rho_{D, t}(z)\right\}} d_{D, t}(z)=\rho_{D, t}(z) y_{D, t}(z)-\frac{w_{t}}{Z_{t} z} y_{D, t}(z), \\
& \max _{\left\{\rho_{V, t}(z)\right\}} d_{V, t}(z)=\rho_{V, t}(z) y_{V, t}(z)-\tau \frac{w_{t}^{*} Q_{t}}{Z_{t}^{*} z} y_{V, t}(z)-f_{V} \frac{w_{t}^{*} Q_{t}}{Z_{t}^{*}},
\end{aligned}
$$

where $\rho_{D, t}(z)$ and $\rho_{V, t}(z)$ are the prices associated with each of the two production strategies, expressed in units of the North consumption basket; $w_{t}$ and $w_{t}^{*}$ are the real wages in the North

\footnotetext{
${ }^{12}$ Thus, one useful feature of the model is that, when offshoring is removed, the model revisits Ghironi and Melitz (2005), which serves as a basis of comparison for some key results.
} 
and the South; and $Q_{t}$ is the real exchange rate. ${ }^{13}$

The cost of producing one unit of output either domestically or offshore varies not only with the cost of effective labor $w_{t} / Z_{t}$ and $w_{t}^{*} Q_{t} / Z_{t}^{*}$ across countries, but also with the idiosyncratic labor productivity $z$ across firms. In addition, the Northern firms producing offshore incur a fixed cost equal to $f_{V}$ units of Southern effective labor, which reflects the building and maintenance of the offshore production facility, ${ }^{14}$ and also an iceberg trade $\operatorname{cost} \tau>1$ associated with the shipping of goods produced offshore back to the parent country. ${ }^{15}$

The demand for the variety of firm $z$ produced either domestically or offshore is $y_{D, t}(z)=$ $\rho_{D, t}(z)^{-\theta} C_{t}$ or $y_{V, t}(z)=\rho_{V, t}(z)^{-\theta} C_{t}$ respectively, where $C_{t}$ is the aggregate consumption in the North. Profit maximization implies the equilibrium prices $\rho_{D, t}(z)=\frac{\theta}{\theta-1} \frac{w_{t}}{Z_{t} z}$ and $\rho_{V, t}(z)=$ $\frac{\theta}{\theta-1} \tau \frac{w_{t}^{*} Q_{t}}{Z_{t}^{*} z}$ for the alternative scenarios of domestic and offshore production. The corresponding profits, expressed in units of the aggregate consumption basket $C_{t}$, are:

$$
\begin{aligned}
d_{D, t}(z) & =\frac{1}{\theta} \rho_{D, t}(z)^{1-\theta} C_{t}, \\
d_{V, t}(z) & =\frac{1}{\theta} \rho_{V, t}(z)^{1-\theta} C_{t}-f_{V} \frac{w_{t}^{*} Q_{t}}{Z_{t}^{*}} .
\end{aligned}
$$

When deciding upon the location of production every period, the firm with productivity $z$ compares the profit $d_{D, t}(z)$ that it would obtain from domestic production with the profit $d_{V, t}(z)$ that it would obtain from producing the same variety offshore. As a particular case, I define the productivity cutoff level $z_{V, t}$ on the support interval $\left[z_{\min }, \infty\right)$, so that the firm at the

\footnotetext{
${ }^{13}$ The real exchange rate $Q_{t}=P_{t}^{*} \varepsilon_{t} / P_{t}$ is the ratio between the price indexes in the South and the North expressed in the same currency, where $\varepsilon_{t}$ is the nominal exchange rate.

${ }^{14}$ The fixed offshoring cost is equivalent to $f_{V} w_{t}^{*} / Z_{t}^{*}$ units of the Southern consumption basket.

${ }^{15}$ For every $\tau>1$ units produced offshore, only one unit arrives in the North for consumption, with the difference lost due to trade barriers, transportation and insurance costs (Anderson and Wincoop, 2004).
} 
cutoff obtains equal profits from producing domestically or offshore:

$$
z_{V, t}=\left\{z \mid d_{D, t}(z)=d_{V, t}(z)\right\}
$$

The model implies that only the relatively more productive Northern firms find it profitable to produce their varieties offshore. Despite the lower cost of effective labor in the South, only firms with idiosyncratic productivity above the cutoff level $\left(z>z_{V, t}\right)$ obtain benefits from offshoring that are large enough to cover the fixed and iceberg trade costs. This implication is consistent with the empirical evidence in Kurz (2006), who shows that the U.S. plants and firms using imported components in production are larger and more productive than their domestically-oriented counterparts, as the larger idiosyncratic productivity levels allow them to cover the fixed costs of offshoring. ${ }^{16}$

In addition, the productivity cutoff $z_{V, t}$ reacts to fluctuations in the relative cost of effective labor across countries, and thus affects the extensive margin of offshoring over the business cycle. For any given level of firm-specific productivity, a relatively lower cost of effective labor abroad implies lower prices, higher revenues, and higher profits from offshoring, and therefore leads to a larger fraction of offshoring firms in equilibrium. This implication is consistent with the empirical evidence on the determinants of offshoring in Hanson, Mataloni, and Slaughter (2005), who show that U.S. multinationals attract larger shares of their foreign affiliates's sales when the latter benefit from lower trade costs and lower wages abroad.

\footnotetext{
${ }^{16} \mathrm{~A}$ useful implication of the model is that more productive firms have larger output and revenue. Given two firms with idiodsyncratic productivity $z_{2}>z_{1}$, their output and profit ratios are $\frac{y\left(z_{2}\right)}{y\left(z_{1}\right)}=\left(\frac{z_{2}}{z_{1}}\right)^{\theta}>1$ and $\frac{d\left(z_{2}\right)}{d\left(z_{1}\right)}=\left(\frac{z_{2}}{z_{1}}\right)^{\theta-1}>1$ (also see Melitz, 2003). This is consistent with the empirical evidence that firms using imported inputs in production are not only more productive, but also have larger revenues and employ more workers (Kurz, 2006).
} 
In equilibrium, the existence of productivity cutoff $z_{V, t}$ requires a cross-country asymmetry in the cost of effective labor, which ensures that some of the Northern firms have an incentive to produce offshore. To illustrate this point, I re-write the per-period profits from domestic and offshore production as $d_{D, t}(z)=M_{t}\left(\frac{w_{t}}{Z_{t}}\right)^{1-\theta} z^{\theta-1}$ and $d_{V, t}(z)=M_{t}\left(\tau \frac{w_{t}^{*} Q_{t}}{Z_{t}^{*}}\right)^{1-\theta} z^{\theta-1}-f_{V} \frac{w_{t}^{*} Q_{t}}{Z_{t}^{*}}$, where $M_{t} \equiv \frac{1}{\theta}\left(\frac{\theta}{1-\theta}\right)^{1-\theta} C_{t}$ measures the size of the Northern market. Figure 1 plots the two profits as functions of the idiosyncratic productivity parameter $z^{\theta-1}$ over the support interval $\left[z_{\min }, \infty\right)$. The vertical intercept is zero for domestic production; it is equal to the negative of the fixed $\operatorname{cost}\left(-f_{V} \frac{w_{t}^{*} Q_{t}}{Z_{t}^{*}}\right)$ for offshoring. In this framework, the productivity cutoff $z_{V, t}$ exists in equilibrium if the profit function from offshoring is steeper than the profit function from domestic production, slope $\left\{d_{V, t}(z)\right\}>$ slope $\left\{d_{D, t}(z)\right\}$. When this condition is met, offshoring generates larger profits than domestic production for the subset of firms with idiosyncratic productivity $z$ along the upper range of the support interval $\left(z>z_{V, t}\right)$. The inequality of profit slopes is equivalent to $\tau T O L_{t}<1$, with the "terms of labor" $T O L_{t}=\frac{Q_{t} w_{t}^{*} / Z_{t}^{*}}{w_{t} / Z_{t}}$ defined as the ratio between the cost of effective labor in the South and the North expressed in the same currency. The condition implies that the effective wage in the South must be sufficiently lower than in the North, so that the difference covers the fixed and iceberg trade cost $(\tau>1)$, and thus provides an incentive for some of the Northern firms to produce offshore. (Note that an appreciation of the terms of labor for the North is equivalent to a decline in $\left.T O L_{t}.\right)$ The model calibration and the magnitude of macroeconomic shocks ensure that this condition is satisfied every period. ${ }^{17}$

\footnotetext{
${ }^{17} \mathrm{~A}$ second condion necessary to avoid the corner solution when all firms would produce offshore is $d_{D, t}\left(z_{\min }\right)>$ $d_{V, t}\left(z_{\min }\right)$. It ensures that $z_{V, t}>z_{\min }$ in all periods.
} 


\subsubsection{Exporting Firms}

In addition to serving their domestic market, firms from each economy can choose to serve the foreign market through exports, as in Ghironi and Melitz (2005). In the North, the firm with idiosyncratic productivity $z$ would use an amount of domestic labor $l_{H, t}(z)$ to produce for the Southern market, $y_{H, t}(z)=Z_{t} z l_{H, t}(z)$. The Southern firms that choose to export to the North face a similar problem.

Profit maximization implies the following equilibrium price: $\rho_{H, t}(z)=\frac{\theta}{\theta-1} \tau^{*} \frac{w_{t} Q_{t}^{-1}}{Z_{t} z}$ and profit function: $d_{H, t}(z)=\frac{1}{\theta} \rho_{H, t}(z)^{1-\theta} C_{t}^{*} Q_{t}-f_{H} \frac{w_{t}}{Z_{t}}$ for the Northern exporter with productivity factor $z$, where $C_{t}^{*}$ is aggregate consumption in the South. Producing for the foreign market generates additional profits, but involves a fixed exporting cost equal to $f_{H}$ units of Northern effective labor, and also an iceberg trade $\operatorname{cost} \tau^{*}$. The model implies that only the subset of Northern firms with idiosyncratic labor productivity above the productivity cutoff $z_{H, t}$ find it profitable to produce in North and export to the Southern market, as they can afford the fixed and iceberg trade costs of exporting. Thus, the time-varying productivity cutoff for exporters is:

$$
z_{H, t}=\inf \left\{z \mid d_{H, t}\left(z_{V, t}\right)>0\right\}
$$

\subsubsection{Offshoring and Exporting Firms}

In the stylized model of vertical FDI proposed in this paper, the offshoring and exporting activities of Northern firms are driven by separate objectives, namely by selling to the home vs. foreign markets respectively. In an alternative model, offshoring firms could also sell to the foreign market - in addition to the home market - if given the opportunity, either directly by engaging in export-substituting horizontal FDI as in Helpman, Melitz and Yeaple 
(2004), or indirectly by re-routing the varieties through the home country. However, such a setup would provide different incentives to the offshoring firms, and would have different macroeconomic implications than offshoring through vertical FDI, which is the focus of this paper. This choice is guided by a number of reasons, including that vertical FDI is the type of offshoring associated with the maquiladora stylized facts presented earlier. In addition, offshoring through vertical FDI is associated with the empirical relation between offshoringrelated trade and output comovement documented in BKT, since it boosts trade rather than substitutes it (see Ramondo and Rodriguez-Clare, 2012). Finally, with offshoring through vertical FDI, the offshoring output is part of the foreign economy but is affected by demand in home, which has important implications for output comovement.

One implication from the family of models with heterogeneous firms is that firms self-select themselves into exporting and offshoring activities from the higher end of the productivity distribution. Thus, in this model, there are cases in which the offshoring and exporting operations are undertaken by firms with similar productivity, although these activities target different markets. ${ }^{18}$ The implication is consistent with empirical evidence that both exporting and importing firms are relatively more productive (Bernard, Jensen, Redding, Schott, 2007), and also that exporting and offshoring activities may occur simultaneously within the same firm (Kurz, 2006). It is also consistent with firms whose globalization strategy involves offshoring to a low-wage country at the same time with producing in the home base for reasons other than vertical integration, such as diversifying supply chain risks and reducing inventory costs (Economist, 2011).

\footnotetext{
${ }^{18} \mathrm{~A}$ model with heterogeneous firms that combines offshoring through vertical FDI (as in this paper) with exports and horizontal FDI (as in Helpman, Melitz and Yeaple, 2004) would yield a similar implication when the productivity cutoff for vertical FDI is below that for horizontal FDI.
} 


\section{Aggregation over Heterogeneous Firms}

This section translates the model with a continuum of heterogeneous firms into an equivalent framework with two average representative Northern firms that produce domestically and offshore, respectively, for their domestic market. Since offshoring takes place one-way, there is only one representative Southern firm that produces for the South market. In addition, one representative firm in each economy produces domestically for the export market.

\subsection{Average Firm Productivity Levels}

Domestic vs. offshore production: First I describe the average productivity levels of the two representative Northern firms that produce domestically and offshore for the Northern market. Figure 2 plots the density of the firm-specific labor productivity levels $z$ over the support interval $\left[z_{\text {min }}, \infty\right)$. Every period $t$, there are $N_{D, t}$ firms from the North with idiosyncratic productivity factors below the offshoring cutoff $\left(z<z_{V, t}\right)$ that produce domestically; their average productivity is $\widetilde{z}_{D, t}$. There are also $N_{V, t}$ firms with productivity factors above the cutoff $\left(z>z_{V, t}\right)$ that choose to produce offshore; their average productivity is $\widetilde{z}_{V, t}$. Since the firm-specific labor productivity levels $z$ are random draws from a common distribution $G(z)$ with density $g(z)$, I compute the two average productivity levels as:

$$
\widetilde{z}_{D, t}=\left[\frac{1}{G\left(z_{V, t}\right)} \int_{z_{\min }}^{z_{V, t}} z^{\theta-1} g(z) d z\right]^{\frac{1}{\theta-1}} \quad \text { and } \quad \widetilde{z}_{V, t}=\left[\frac{1}{1-G\left(z_{V, t}\right)} \int_{z_{V, t}}^{\infty} z^{\theta-1} g(z) d z\right]^{\frac{1}{\theta-1}} \text {. }
$$

I assume that the firm-specific labor productivity draws $z$ are Pareto-distributed, with p.d.f.

$g(z)=k z_{\text {min }}^{k} / z^{k+1}$ and c.d.f. $G(z)=1-\left(z_{\min } / z\right)^{k}$ over the support interval $\left[z_{\min }, \infty\right)$. Using this assumption, I derive analytical solutions for the average productivity levels of the two 
representative Northern firms that produce domestically and offshore as functions of the timevariant productivity cutoff $z_{V, t}:{ }^{19}$

$$
\widetilde{z}_{D, t}=\nu z_{\min } z_{V, t}\left[\frac{z_{V, t}^{k-(\theta-1)}-z_{\min }^{k-(\theta-1)}}{z_{V, t}^{k}-z_{\min }^{k}}\right]^{\frac{1}{\theta-1}} \quad \text { and } \quad \widetilde{z}_{V, t}=\nu z_{V, t},
$$

where the productivity cutoff is $z_{V, t}=z_{\min }\left(N_{t} / N_{V, t}\right)^{(1 / k)}$, and the parameters are $\nu \equiv\left[\frac{k}{k-(\theta-1)}\right]^{\frac{1}{\theta-1}}$ and $k>\theta-1 .{ }^{20}$ Since offshoring takes place one-way, from the North to the South, the Southern firms serve their domestic market exclusively through domestic production. Their average productivity is constant, $\widetilde{z}_{D}^{*}=\nu z_{\min }^{*}$, as it covers the entire support interval $\left[z_{\min }^{*}, \infty\right)$.

Exporting firms: Under the Pareto assumption, the average productivity levels of the exporting firms in each economy are as in Ghironi and Melitz (2005):

$$
\widetilde{z}_{H, t}=\nu z_{\min }\left(\frac{N_{t}}{N_{H, t}}\right)^{1 / k} \quad \text { and } \quad \widetilde{z}_{H, t}^{*}=\nu z_{\min }^{*}\left(\frac{N_{D, t}^{*}}{N_{H, t}^{*}}\right)^{1 / k} \text {. }
$$

\subsection{Average Prices and Profits}

Using the average productivity levels for the domestic, offshoring and exporting firms defined in Section 3.1, I translate the model of offshoring in terms of three representative Northern firms: one produces domestically, another produces offshore (each serving the Northern market), while a third firm produces domestically and exports to the Southern market. There are only two representative Southern firms: one produces for the local market, and the other exports to the

\footnotetext{
${ }^{19}$ The derivations are shown in the Technical Appendix available online.

${ }^{20}$ I use the Pareto c.d.f. $G\left(z_{V, t}\right)=1-\left(z_{\min } / z_{V, t}\right)^{k}$ and the share of Northern firms producing offshore $N_{V, t} / N_{t}=1-G\left(z_{V, t}\right)$ to write the productivity cutoff as $z_{V, t}=z_{\min }\left(N_{t} / N_{V, t}\right)^{(1 / k)}$. The share of Northern firms producing domestically is $N_{D, t} / N_{t}=G\left(z_{V, t}\right)$. Parameter $k$ reflects the dispersion of the productivity draws: A relatively larger $k$ implies a smaller dispersion and a higher concentration of productivities $z$ towards the lower productivity bound $z_{\text {min }}$.
} 
North. The average prices and profits for each representative firm are in Table 1.

Using the property that the Northern firm at the productivity cutoff $z_{V, t}$ is indifferent between the two production strategies, I derive the following relationship between the average profits of the two representative firms that produce domestically and offshore: ${ }^{21}$

$$
\widetilde{d}_{V, t}=\frac{k}{k-(\theta-1)}\left(\frac{z_{V, t}}{\widetilde{z}_{D, t}}\right)^{\theta-1} \widetilde{d}_{D, t}+\frac{\theta-1}{k-(\theta-1)} f_{V} \frac{w_{t}^{*} Q_{t}}{Z_{t}^{*}} .
$$

In addition, using the property that the firm at the productivity cutoff $z_{H, t}$ obtains zero profits from exporting, the average profits from exports are as in Ghironi and Melitz (2005):

$$
\widetilde{d}_{H, t}=\frac{\theta-1}{k-(\theta-1)} f_{H} \frac{w_{t}}{Z_{t}} \text { and } \widetilde{d}_{H, t}^{*}=\frac{\theta-1}{k-(\theta-1)} f_{H}^{*} \frac{w_{t}^{*}}{Z_{t}^{*}} .
$$

Price indexes and total profits The consumption price indexes in the North and the South are functions of the average prices of varieties available in each economy:

$$
\begin{aligned}
& 1=N_{D, t}\left(\widetilde{\rho}_{D, t}\right)^{1-\theta}+N_{V, t}\left(\widetilde{\rho}_{V, t}\right)^{1-\theta}+N_{H, t}^{*}\left(\widetilde{\rho}_{H, t}^{*}\right)^{1-\theta} . \\
& 1=N_{D, t}^{*}\left(\widetilde{\rho}_{D, t}^{*}\right)^{1-\theta}+N_{H, t}\left(\widetilde{\rho}_{H, t}\right)^{1-\theta} .
\end{aligned}
$$

Finally, total profits are based on the average profits and the number of firms in each economy:

$$
\begin{aligned}
N_{t} \widetilde{d}_{t} & =N_{D, t} \widetilde{d}_{D, t}+N_{V, t} \widetilde{d}_{V, t}+N_{H, t} \widetilde{d}_{H, t} . \\
N_{D, t}^{*} \widetilde{d}_{t} & =N_{D, t}^{*} \widetilde{d}_{D, t}^{*}+N_{H, t}^{*} \widetilde{d}_{H, t}^{*} .
\end{aligned}
$$

\footnotetext{
${ }^{21}$ See the Technical Appendix available online for details.
} 


\subsection{Aggregate Accounting and the Current Account}

Aggregate output is equal to the sum of labor income and stock dividends that households in each economy obtain every period, $Y_{t}=w_{t} L+N_{t} \widetilde{d}_{t}$ and $Y_{t}^{*}=w_{t}^{*} L^{*}+N_{D, t}^{*} \widetilde{d}_{t}^{*}$. Thus, the value added offshore, $\mathrm{VA}_{t}=N_{V, t}\left[\frac{\theta-1}{\theta \tau}\left(\widetilde{\rho}_{V, t}\right)^{1-\theta} C_{t}+f_{V} \frac{w_{t}^{*} Q_{t}}{Z_{t}^{*}}\right]$, defined as the wage income of Southern workers employed for the production and fixed cost activities in the offshoring sector, is part of the Southern output. ${ }^{22}$ The profits of Northern firms that produce offshore are part of the Northern output. Under financial autarky in the markets for bonds and stocks, aggregate accounting implies that households spend their income from labor and stock holdings on consumption and investment in new firms, $C_{t}+N_{E, t} \widetilde{v}_{t}=Y_{t}$ and $C_{t}^{*}+N_{E, t}^{*} \widetilde{v}_{t}^{*}=Y_{t}^{*}$.

The current account in the North is:

$$
C A_{t}=\underbrace{N_{H, t}\left(\widetilde{\rho}_{H, t}\right)^{1-\theta} C_{t}^{*} Q_{t}}_{\text {(a) Exports }}+\underbrace{N_{V, t} \widetilde{d}_{V, t}}_{\text {(b) Repatriated profits }}-\underbrace{N_{V, t}\left(\widetilde{\rho}_{V, t}\right)^{1-\theta} C_{t}}_{\text {(c) Value added offshore }}-\underbrace{N_{H, t}^{*}\left(\widetilde{\rho}_{H, t}^{*}\right)^{1-\theta} C_{t}}_{\text {(d) Imports of Southern varieties }}
$$

Under financial autarky, the balanced current account condition $\left(C A_{t}=0\right)$ implies that the sum of (a) exports by Northern firms to the South and (b) repatriated profits of offshore affiliates must be equal to the sum of (c) the value added offshore imported by the North and (d) the imports of varieties produced by the Southern firms. ${ }^{23}$

\subsection{Summary of Baseline Model}

The baseline model with financial autarky for the Northern economy is characterized by 16 equations in 16 endogenous variables: $N_{t}, N_{D, t}, N_{V, t}, N_{H, t}, N_{E, t}, \widetilde{d}_{t}, \widetilde{d}_{D, t}, \widetilde{d}_{V, t}, \widetilde{d}_{H, t}, \widetilde{z}_{D, t}, \widetilde{z}_{V, t}$,

\footnotetext{
${ }^{22}$ The inclusion of the fixed cost in $\mathrm{VA}_{t}$ has minimal implications for the value added dynamics (see Figure D.3 in the Technical Appendix online).

${ }^{23}$ In the case with international trade in bonds, the current account balance equals the change in bond holdings (see the Appendix).
} 
$\widetilde{z}_{H, t}, \widetilde{v}_{t}, r_{t}, w_{t}$ and $C_{t}$. Since the Southern firms do not produce in the high-cost North, the Southern economy is described by only 11 equations in 11 endogenous variables; there are no Southern counterparts for $N_{t}, N_{V, t}, \widetilde{d}_{V, t}, \widetilde{z}_{D, t}$ and $\widetilde{z}_{V, t}{ }^{24}$ Finally, the real exchange rate $Q_{t}$ and the current account equation close the model.

\subsection{Calibration}

I use a standard quarterly calibration by setting the subjective rate of time discount $\beta=0.99$ to match an average annualized interest rate of 4 percent. The coefficient of relative risk aversion is $\gamma=2$. Following Ghironi and Melitz (2005), the intra-temporal elasticity of substitution is $\theta=3.8$, and the probability of firm exit is $\delta=0.025$, which matches annual 10 percent job destruction in the United States.

As summarized in Table 2, the Pareto distribution parameter $k$, the iceberg trade $\operatorname{cost} \tau$, and the fixed costs of offshoring $\left(f_{V}\right)$ and exporting $\left(f_{H}\right.$ and $\left.f_{H}^{*}\right)$ are calibrated so that the model in steady state matches the importance of offshoring for the Mexican economy, as illustrated by three empirical moments: (1) The maquiladora value added represents about 20 percent of Mexico's manufacturing GDP (Bergin et al., 2009), vs. 20 percent in the model in steady state; (2) The maquiladora sector provided about 55 percent of Mexico's manufacturing exports on average from 2000 to 2006 (INEGI, 2008), compared to about 60 percent in the model; (3) The maquiladora sector accounts for about 25 percent of Mexico's manufacturing employment (Bergin et al., 2009), vs. 20 percent in the model. To this end, I set $k=4.2, \tau=1.2$, $f_{V}=0.095, f_{H}=0.040$ and $f_{H}^{*}=0.025$. Without loss of generality, the lower bound of the

\footnotetext{
${ }^{24}$ The model summary is in the Appendix, and the asymmetric steady-state solution is available in the Technical Appendix. Note that the average labor productivity of the representative Southern firm producing for the domestic market $\left(\widetilde{z}_{D}^{*}\right)$ is constant over time. Variables $N_{D, t}, r_{t}, N_{t}^{*}$ and $r_{t}^{*}$ are predetermined.
} 
support interval for firm-specific productivity in the North and the South is $z_{\min }=z_{\min }^{*}=1$.

To obtain an asymmetric cost of effective labor across countries in steady state, the sunk entry cost, which reflects headquarter costs sensitive to the regulation of starting a business in the firms' country of origin, is set to be larger in the South than in the North $\left(f_{E}^{*}=4 f_{E}\right.$ and $\left.f_{E}=1\right)$. As a result, the steady-state number of firms, the labor demand and the effective wage are relatively lower in the South. The calibration reflects the considerable variation in the monetary cost of starting a business across economies, which was 2.8 times higher in Mexico than in the United States in purchasing power parity terms in 2010 (World Bank, 2011). The asymmetric sunk entry costs, along with the values for $k, \tau, f_{V}, f_{H}$ and $f_{H}^{*}$ discussed above, generate a steady-state value for the terms of labor that is less than unit $\left(T O L=\frac{Q w^{*} / Z^{*}}{w / Z}=0.75\right)$. In other words, the steady-state cost of effective labor in the South is 75 percent of the cost of effective labor in the North. Thus, the calibration provides an incentive for some of the Northern firms to produce offshore in steady state. ${ }^{25}$

\section{Alternative Models}

This section presents the alternative models with endogenous labor supply and investment in physical capital.

\footnotetext{
${ }^{25}$ The resulting steady-state fraction of the Northern firms that use foreign labor $\left(N_{V} / N\right)$ is 1 percent; the fraction of exporting firms $\left(N_{H} / N\right)$ is 9 percent. Since offshoring is modelled in an asymmetric two-country framework that abstracts from the trade of U.S. firms with the rest of the world other than Mexico, the steadystate values reported above are less than their empirical counterparts. In the data, 14 percent of the U.S. firms (other than domestic wholesalers) used imported inputs in 1997 (Bernard, Jensen, Redding and Schott, 2007); 21 percent of the U.S. manufacturing plants were exporters in 1992 (Bernard, Eaton, Jensen and Kortum, 2003).
} 


\subsection{Endogenous Labor Supply}

With endogenous labor supply, the representative household in the North maximizes the expected lifetime utility $\max _{\left\{L_{t}, x_{t}, B_{t}\right\}}\left[E_{t} \sum_{s=t}^{\infty} \beta^{s-t} U\left(C_{s}, L_{s}\right)\right]$, with the discount factor $\beta \in(0,1)$. The period utility function takes the form: $U_{t}\left(C_{t}, L_{t}\right)=\ln C_{t}-\chi \frac{L_{t}^{1+\psi}}{1+\psi}$, in which $C_{t}$ denotes consumption, $L_{t}$ is the variable labor supply, $\psi>0$ is the inverse elasticity of labor supply, and $\chi>0$ is the weight on the disutility from labor. In the North, the Euler equation for bonds is: $C_{t}^{-1}=\beta\left(1+r_{t+1}\right) E_{t}\left[C_{t+1}^{-1}\right]$, the equation for labor supply is: $L_{t}=\left(\frac{w_{t}}{\chi C_{t}}\right)^{1 / \psi}$, and the equation for aggregate accounting changes to incorporate endogenous labor supply: $C_{t}+N_{E, t} \widetilde{v}_{t}=w_{t} L_{t}+N_{t} \widetilde{d}_{t}$. The corresponding equations for the South are similar. ${ }^{26}$

\subsection{Physical Capital}

The model with physical capital includes four new variables and four new equations for each economy. For the North, $K_{t}$ is the stock of physical capital, $I_{t}$ is investment in physical capital, $r_{t}^{k}$ is the gross return from capital, and $\lambda_{t}$ is the multiplier on the new equation of capital accumulation, which takes the form:

$$
K_{t+1}=\left(1-\delta^{k}\right) K_{t}+I_{t}-\frac{\pi^{k}}{2} I_{t-1}\left(\frac{I_{t}}{I_{t-1}}-1\right)^{2}
$$

where $\pi^{k}$ denotes an investment adjustment cost. In addition, the budget constraint of the representative household becomes: $\left(\widetilde{v}_{t}+\widetilde{d}_{t}\right) N_{t} x_{t}+w_{t} L+r_{t}^{k} K_{t} \geqslant \widetilde{v}_{t}\left(N_{t}+N_{E, t}\right) x_{t+1}+C_{t}+I_{t}$.

\footnotetext{
${ }^{26}$ In a robustness check, to mute the income effect on labor supply, I use preferences as in Greenwood, Hercowitz and Huffman $(\mathrm{GHH}, 1988)$, with $U_{t}\left(C_{t}, L_{t}\right)=\frac{1}{1-\gamma}\left[\left(C_{t}-\chi \frac{L_{t}^{1+\psi}}{1+\psi}\right)^{1-\gamma}-1\right]$. The equation for labor supply becomes $L_{t}=\left(\frac{w_{t}}{\chi}\right)^{1 / \psi}$.
} 
Thus, the first-order conditions for capital and investment are:

$$
\begin{aligned}
& \lambda_{t}=\beta E_{t}\left[C_{t+1}^{-\gamma} r_{t+1}^{k}\right]+\beta\left(1-\delta^{k}\right) E_{t}\left[\lambda_{t+1}\right], \\
& C_{t}^{-\gamma}=\lambda_{t}\left[1-\pi^{k}\left(\frac{I_{t}}{I_{t-1}}-1\right)\right]+\beta E_{t}\left[\lambda_{t+1} \frac{\pi^{k}}{2}\left(\left(\frac{I_{t}}{I_{t-1}}\right)^{2}-1\right)\right] .
\end{aligned}
$$

The equation for aggregate accounting is adjusted to include the investment and gross return from physical capital: $N_{t} \widetilde{d}_{t}+w_{t} L+r_{t}^{k} K_{t}=N_{E, t} \widetilde{v}_{t}+C_{t}+I_{t}$. Importantly, the composite good that incorporates domestic, offshored and foreign varieties is used for both consumption and investment: $C_{t}+I_{t}=\left[\int_{z_{\min }}^{z_{V, t}} y_{D, t}(\omega)^{\frac{\theta-1}{\theta}} d \omega+\int_{z_{V, t}}^{\infty} y_{V, t}(\omega)^{\frac{\theta-1}{\theta}} d \omega+\int_{z_{H, t}^{*}}^{\infty} y_{H, t}^{*}(\omega)^{\frac{\theta-1}{\theta}} d \omega\right]^{\frac{\theta}{\theta-1}}$.

For each variety $z$, production is a function of labor and capital, and takes the form $y_{D, t}(z)=Z_{t} z\left[l_{t}(z)\right]^{1-\alpha}\left[k_{t}(z)\right]^{\alpha}$ for domestic production, and $y_{V, t}(z)=Z_{t}^{*} z\left[l_{t}^{*}(z)\right]^{1-\alpha}\left[k_{t}^{*}(z)\right]^{\alpha}$ for offshoring. The corresponding prices are $\rho_{D, t}(z)=\frac{\theta}{\theta-1} \frac{1}{Z_{t} z}\left(\frac{w_{t}}{1-\alpha}\right)^{1-\alpha}\left(\frac{r_{t}^{k}}{\alpha}\right)^{\alpha}$ if variety $z$ is produced at home, and $\rho_{V, t}(z)=\frac{\theta}{\theta-1} \frac{\tau Q_{t}}{Z_{t}^{*} z}\left(\frac{w_{t}^{*}}{1-\alpha}\right)^{1-\alpha}\left(\frac{r_{t}^{* k}}{\alpha}\right)^{\alpha}$ if it is offshored. In addition, firm entry in the North implies a sunk cost activity that requires effective units of domestic labor and capital, and thus is equal to $\frac{f_{E}}{Z_{t}}\left(\frac{w_{t}}{1-\alpha}\right)^{1-\alpha}\left(\frac{r_{t}^{k}}{\alpha}\right)^{\alpha}$ units of the North consumption basket. Also, offshoring implies a fixed cost activity that requires effective units of foreign labor and capital, and thus is equal to $\frac{f_{V}}{Z_{t}^{*}}\left(\frac{w_{t}^{*}}{1-\alpha}\right)^{1-\alpha}\left(\frac{r_{t}^{* k}}{\alpha}\right)^{\alpha}$ units of the South consumption basket. Similarly, the fixed cost of exporting is $\frac{f_{H}}{Z_{t}}\left(\frac{w_{t}}{1-\alpha}\right)^{1-\alpha}\left(\frac{r_{t}^{k}}{\alpha}\right)^{\alpha}$. Thus, the market clearing condition for the stock of capital in the North incorporates capital used by the firms producing domestically for the home and foreign market, as well as capital used for the sunk entry cost and fixed exporting cost activities:

$$
K_{t}=N_{D, t} \widetilde{k}_{D, t}+N_{H, t} \widetilde{k}_{H, t}+\left(N_{E, t} \frac{f_{E}}{Z_{t}}+N_{H, t} \frac{f_{H}}{Z_{t}}\right)\left[\frac{\alpha w_{t}}{(1-\alpha) r_{t}^{k}}\right]^{1-\alpha} .
$$


The market clearing condition for the South is similar, but also includes capital used by the offshoring firms from North for production and fixed cost activities in the South.

Finally, in the presence of physical capital, the terms of labor $T O L_{t}=\frac{Q_{t} w_{t}^{*} / Z_{t}^{*}}{w_{t} / Z_{t}}$ are no longer an adequate measure of the relative cost of production across countries. Instead, I define the "terms of production" as the ratio between the marginal cost of production in the South and the North expressed in units of the same currency: $T O P_{t}=\frac{Q_{t}\left(w_{t}^{*}\right)^{1-\alpha}\left(r_{t}^{* k}\right)^{\alpha} / Z_{t}^{*}}{\left(w_{t}\right)^{1-\alpha}\left(r_{t}^{k}\right)^{\alpha} / Z_{t}}$. The model of offshoring with physical capital is summarized in Table A.3 of the Appendix.

\subsection{Calibration of alternative models}

In the model with elastic labor supply, the elasticity of labor supply is $1 / \psi=1$ in both the North and the South, as in Farhat (2009), and the weight on the disutility from labor is set at $\chi=0.9208$ in the North and $\chi^{*}=0.9466$ in the South, so that labor supply in state state matches that in the baseline model, $L=L^{*}=1 .^{27}$

In the model with physical capital, the coefficient on capital in production and sunk/fixed cost activities is set at $\alpha=0.37$ in both economies, so that the share of capital in aggregate income (which includes income from capital, labor as well as firm profits) is about 0.3. The fixed costs of offshoring and exporting are re-set at $f_{V}=0.44, f_{H}=0.032$ and $f_{H}^{*}=0.027$, so that trade openness in the North and the South, as well as the importance of offshoring for the Southern economy (i.e. 22 percent of GDP, 57 percent of exports, and 21 percent of employment) are similar to the baseline model. Since investment in physical capital and firm entry are substitute options for the Northern household, their relative volatility has a non-trivial effect on model implications (see Fattal Jaef and Lopez, 2012). Therefore, the adjustment cost

\footnotetext{
${ }^{27}$ With GHH preferences, the inverse inter-termporal elasticity of substitution is $\gamma=1$; the inverse elasticity of labor supply is $\psi=1$, and the weights are $\chi=2.451$ and $\chi^{*}=1.481$ so that, in steady state, $L=L^{*}=1$.
} 
of investment in physical capital is set at $\pi^{k}=\pi^{* k}=1.35$, so that the volatility of firm entry matches that of investment in physical capital, as in the data. ${ }^{28}$

\section{Results}

\subsection{Offshoring to Mexico's Maquiladora Sector}

This section describes empirically the cyclicality of offshoring motivated by lower production costs, using data from U.S. manufacturing and Mexico's maquiladora sector as an example. The empirical exercise will be useful to assess the model implications, which are described next.

Mexico's maquiladora sector represents an appropriate empirical setup to study the cyclicality of offshoring motivated by lower production costs, due to its direct links to U.S. manufacturing and the absence of local consumption in Mexico. The maquiladora sector consists of plants that import inputs, process them, and export the resulting output back to the country of origin (see Gruben, 2001). Although only a subset of the maquiladora plants are U.S.-owned, most of them accommodate the offshoring operations of U.S. firms: The maquiladoras import most of their production inputs from the United States (82 percent), and likewise export most of their output to the United States (90 percent; see Hausman and Haytko, 2003; Burstein, Kurz and Tesar, 2008). The maquiladora value added is part of Mexico's manufacturing output.

Empirical cross-correlations Mexico's manufacturing production and, in particular, the maquiladora value added are strongly correlated with the U.S. manufacturing production. Panel 1 of Figure 3 plots the detrended series for Mexico's maquiladora real value added (dashed

\footnotetext{
${ }^{28}$ Using the data on new establishments from the Business Dynamics Statistics of the U.S. Census Bureau, Fattal Jaef and Lopez (2012) show that firm entry is at least as volatile as investment.
} 
line), Mexico's manufacturing industrial production (Mex IP, dotted line), and the U.S. manufacturing industrial production (US IP, solid line), for the interval from 1990:Q1 to 2006:Q4 for which the maquiladora data are available. ${ }^{29}$ The chart shows that the U.S. recessions in 1990 and 2001, as well as the expansion throughout the late 1990s were associated with similar developments in Mexico. Also, during the 1994-95 financial crisis in Mexico, the decline in the maquiladora value added was less pronounced than the drop in Mexico's manufacturing IP, as the offshoring sector benefited from its direct links with U.S. manufacturing. In panel 2, the cross-correlations show that Mexico's maquiladora value added comoves more closely with the U.S. manufacturing IP than does Mexico's total manufacturing IP: the contemporaneous correlation between the maquiladora value added the U.S. manufacturing IP (0.69) is larger than the correlation between the Mexican and U.S. manufacturing IP (0.58).

Panel 3 of Figure 3 plots the detrended series for the number of maquiladora plants in Mexico (dashed line) - which is a proxy for the extensive margin of offshoring - and also the U.S. manufacturing IP (solid line). The cross-correlations in panel 4 show that the contemporaneous correlation is positive, and that the U.S. manufacturing IP leads the number of maquiladora plants by about four quarters. The result suggests that the extensive margin of offshoring adjusts gradually over time, whereas the maquiladora value added is contemporaneously correlated with the U.S. manufacturing IP. ${ }^{30}$

\footnotetext{
${ }^{29}$ The data are seasonally adjusted, converted in natural logs, and expressed in deviations from a HodrickPrescott trend. The maquiladora series were discontinued at the end of 2006.

${ }^{30}$ These results are consistent with the empirical impulse responses of offshoring to Mexico (including the extensive margin) from the structural VAR model discussed in Section $\mathrm{C}$ the Technical Appendix avilable online.
} 


\subsection{Impulse Responses}

To illustrate the model implications for offshoring, I log-linearize the model around the steady state, and compute the impulse responses to a transitory one-percent increase in aggregate productivity in the North. Aggregate productivity follows the autoregressive process $\log Z_{t+1}=$ $\rho \log Z_{t}+u_{t}$, with persistence $\rho=0.9$.

Figure 4 shows the impulse responses of the baseline model of offshoring (thick solid lines), and compares them with the impulse responses from two alternative models: (i) a model of offshoring in which the productivity cutoff is fixed, so that the fraction of offshoring firms is constant over the business cycle (thin solid lines); ${ }^{31}$ and (ii) the extreme case with no offshoring, which revisits the model with exports only in Ghironi and Melitz (2005) (dashed lines). ${ }^{32}$ For each variable, the horizontal axis illustrates quarters after the initial shock, and the vertical axis shows the percent deviations from the original steady state in each quarter.

The intensive margin In the baseline model (thick solid lines), on impact, the increase in aggregate labor productivity in the North generates a proportional increase in the real wage $\left(w_{t}\right)$. The increase in demand for aggregate consumption, which includes varieties produced both domestically and offshore as imperfect substitutes, causes an immediate increase in the value added per offshoring firm (the intensive margin). ${ }^{33}$ In turn, since the increase in aggregate productivity in the North is not replicated in the South, the excess demand for Southern effective

\footnotetext{
${ }^{31}$ In the alternative model with fixed productivity cutoff, the fraction of offshoring firms is constant, but the number of offshoring firms varies over time due to firm entry in the parent country. During expansions in the North, the new entrants that draw idiosyncratic productivity factors above the cutoff start by producing directly offshore. However, none of the firms that initially produce at home can relocate offshore when the terms of labor appreciate.

${ }^{32}$ In the alternative model with exports only (Ghironi and Melitz, 2005), I set $f_{H}=0.0330$ and $f_{H}^{*}=0.0315$ so that the fraction of Northern exporting firms (9 percent) and that of Southern exporting firms (53 percent) match the corresponding steady-state values from the baseline model with offshoring.

${ }^{33}$ The immediate increase in the intensive margin would be stronger with a lower elasticity of substitution between varieties produced domestically and offshore (see Figure D.2 in the Technical Appendix online).
} 
labor causes the real wage in the South $\left(w_{t}^{*}\right)$ to rise, and the terms of labor $\left(T O L_{t}=\frac{Q_{t} w_{t}^{*} / Z_{t}^{*}}{w_{t} / Z_{t}}\right)$ to depreciate (increase) on impact. As a result, the number of offshoring firms $\left(N_{V, t}\right)$ falls initially, due to the increase in the cost of effective labor offshore and the fixed cost of offshoring, both of which are sensitive to the effective wage in the South. However, the increase in value added per offshoring firms (the intensive margin) more than offsets the initial decline in the number of offshoring firms (the extensive margin), and thus the total value added offshore increases on impact.

The extensive margin In the quarters after the shock, the role of the two margins in driving the procyclical pattern of offshoring is reversed: the extensive margin increases gradually over time, while the intensive margin declines. As aggregate productivity in the North persists above its steady state, the larger market size encourages firm entry, as shown by the gradual increase in the number of incumbent firms $\left(N_{t}\right)$. In turn, firm entry leads to an increase in demand for Northern labor, which causes the cost of effective labor to appreciate gradually in the North relative to the South. In Figure 4, this appreciation is visible as the real wage in the North declines more slowly than aggregate productivity after the initial shock, and thus the terms of labor appreciate (fall) relative to their steady-state level. Following the appreciation of the terms of labor, the number of offshoring firms $\left(N_{V, t}\right)$ increases gradually like in the data, as some of the more productive Northern firms relocate production to the South, while the intensive margin declines. Thus, the increase in the extensive margin more than offsets the intensive margin decline, reinforcing the procyclical pattern of offshoring in the quarters after the shock.

The total value added offshore $\left(V A_{t}\right)$ increases by more under the baseline model of off- 
shoring (thick solid line) than in the alternative model of offshoring in which the productivity cutoff is fixed (thin solid line). Thus, 20 quarters after the shock, roughly one quarter of the increase in the total value added offshore is due to the extensive margin adjustment.

In the South, the initial jump in the real wage, caused by the increase in offshoring along its intensive margin, is followed by an additional increase which occurs gradually over time, as some of the more productive Northern firms relocate production to the South. Since the increase in offshoring along its extensive margin transfers some of the upward pressure from the domestic to the foreign wage, the terms of labor appreciate by less (declines by less) in the baseline model of offshoring (thick solid line) than in the alternative model with no offshoring as in Ghironi and Melitz (2005) (dashed line).

International bond trading Figure 5 shows the impulse responses for the model with international bond trading (thin solid lines), which in general are similar to those from the baseline model (thick lines). One difference is that, following the positive technology shock in the North, the terms of labor do not depreciate (rise) on impact, and hence the number of offshoring firms does not fall, while the total value added offshore rises on impact by more than under financial autarky. The reason is that, since the Southern household lends to the North, firm entry rises more strongly in the North and falls by more in the South, thus placing more upward pressure on the North wage and less on the South wage.

Elastic labor supply Figure 6 shows the impulse responses to the positive shock to productivity in the North for the model with elastic labor supply (the thin solid lines, in green), and compares them to those for the baseline model with fixed labor supply (the thick solid lines, in black). With elastic labor supply, the response of offshoring is similar to the 
baseline model, but is stronger in the quarters after the shock.

On impact, the equilibrium real wage in the North rises along with aggregate productivity, like in the baseline model. Although dampened somewhat by the income effect, labor supply rises in response to the higher wage. However, labor demand rises by even more than in the baseline model, reflecting the stronger entry of new firms attracted by the increased supply of more productive labor, and also by the larger market size resulting from higher labor income. Thus, the immediate wage response is similar to that from the baseline model.

In the quarters after the shock, the number of incumbent firms in the North increases by more than in the baseline model, boosting the demand for labor. In contrast, labor supply falls below its steady-state level due to the income effect associated with higher consumption. As a result, the terms of labor appreciate by more, and hence the number of offshoring firms and the value added offshore increase by more than in the baseline model. The effect is even stronger for a higher elasticity of labor supply (see the dashed lines, with $1 / \psi=3$ ). ${ }^{34}$

Physical capital Figure 7 shows the impulse responses for the model with physical capital. For comparability with the baseline model, the figure presents two versions of the model with physical capital: one in which the share of capital in production follows the standard calibration ( $\alpha=\alpha^{*}=0.37$, thick lines), and another in which the share of capital is set arbitrarily low $\left(\alpha=\alpha^{*}=0.01\right.$, thin lines). The latter case resembles the baseline model, since investment in physical capital represents a very small share of aggregate income.

The presence of physical capital dampens but does not reverse the dynamics of offshoring.

\footnotetext{
${ }^{34}$ The result also holds when the income effect is shut down using preferences as in Greenwood, Hercowitz and Huffman (1988). As shown in Figure D.4 of the Technical Appendix, without the income effect, the increase in labor supply is still offset by the increase in labor demand, which mirrors the stronger rise in firm entry relative to the baseline model. In turn, following the initial depreciation, the terms of labor appreciate over time relative to the steady-state level, providing an incentive for firms to relocate production offshore. Overall, the total value added offshore rises on impact, and continues to rise in the following quarters.
} 
On impact, firm entry rises by less with the standard calibration than in the baseline-like case, since investment in physical capital substitutes firm entry to some extent, as in Fattal Jaef and Lopez (2012). Also, in the quarters after the shock, the number of incumbent firms in the North increases by less with physical capital, given the slower pace of firm entry, which in turn causes the terms of production to appreciate (fall) by less relative to the baseline model. However, the presence of physical capital does not reverse the procyclicality of firm entry, which still places appreciation pressure on the marginal cost of production in the North relative to the South. As a result, the terms of production fall below their steady-state level. Although more slowly, the number of offshoring firms and the total value offshore increase gradually in the quarters following the shock, like in the baseline model.

\subsection{Business Cycles: Data and Model}

This section presents the contemporaneous and cross-correlations between output in the North and the offshoring sector generated by the model, and compares them to the empirical correlations of offshoring from the United States to Mexico discussed in Section 5.1. Aggregate productivities $Z_{t}$ and $Z_{t}^{*}$ follow the bivariate autoregressive process:

$$
\left[\begin{array}{c}
\log Z_{t} \\
\log Z_{t}^{*}
\end{array}\right]=\left[\begin{array}{cc}
\rho_{Z} & \rho_{Z Z^{*}} \\
\rho_{Z^{*} Z} & \rho_{Z^{*}}
\end{array}\right]\left[\begin{array}{c}
\log Z_{t-1} \\
\log Z_{t-1}^{*}
\end{array}\right]+\left[\begin{array}{l}
\xi_{t} \\
\xi_{t}^{*}
\end{array}\right],
$$

with persistence parameters $\rho_{Z}$ and $\rho_{Z^{*}}<1$, spillovers $\rho_{Z Z^{*}}$ and $\rho_{Z^{*} Z} \geqslant 0$, and normallydistributed, zero-mean technology shocks $\xi_{t}$ and $\xi_{t}^{*}$. To compute the correlations of key model variables, the bivariate productivity process is calibrated for the United States and Mexico, based on the Solow residual estimates for the two economies at quarterly frequency over the 
interval 1987:Q1 to 2003:Q2. For each economy, the natural logarithm of the Solow residual is computed as $\ln \lambda=\ln y-\left(1-\alpha_{\lambda}\right) \ln k-\alpha_{\lambda} \ln n$, using seasonally-adjusted aggregate data on output $(y)$, the capital stock $(k)$ and employment $(n)$ obtained from Silos (2007) for the United States, and Aguiar and Gopinath (2007) for Mexico. ${ }^{35}$ Following Heathcote and Perri (2002), I use the seemingly unrelated regression procedure to estimate the persistence and spillover parameters from the Solow residuals, as well as the variance-covariance matrix of the shocks. ${ }^{36}$ In line with these estimates, the productivity process is calibrated to be more persistent in the United States than in Mexico $\left(\rho_{Z}=0.996>\rho_{Z^{*}}=0.951\right)$, and the spillovers from Mexico to the United States to be close to zero $\left(\rho_{Z Z^{*}}=0.003\right)$, in contrast with the positive U.S.-toMexico spillovers $\left(\rho_{Z^{*} Z}=0.049\right)$. I also set the variance of shocks at $0.00953^{2}$ and covariance at $0.242172 * 10^{-4}$, which implies a correlation of 0.267 .

\subsubsection{Contemporaneous correlations}

Table 3 shows the empirical and model correlations of: (1) output in the North and the South $\operatorname{Corr}\left(Y_{R}, Y_{R}^{*}\right),(2)$ output in the North and the value added offshore $\operatorname{Corr}\left(Y_{R}, V A_{R}\right)$, and (3) output in the North and the number of offshoring plants $\operatorname{Corr}\left(Y_{R}, N_{V}\right)$, obtained with the bivariate productivity process calibrated for the United States and Mexico. ${ }^{37}$

In the model, the contemporaneous correlation between output in the North and the value added offshore is larger than the correlation between total output in the North and the South,

\footnotetext{
${ }^{35}$ Silos (2007) uses $\alpha_{\lambda}=0.64$ for the United States; Aguiar and Gopinath (2007) use $\alpha_{\lambda}=0.68$ for Mexico.

${ }^{36}$ The estimates of persistence and spillover parameters are $A=\left[\begin{array}{ll}0.996(0.014) & 0.003(0.015) \\ 0.049(0.040) & 0.951(0.040)\end{array}\right]$; standard errors are reported in parantheses. Also, $\operatorname{var}\left(\xi_{t}\right)=0.0051^{2}, \operatorname{var}\left(\xi_{t}^{*}\right)=0.0140^{2}$ and $\operatorname{corr}\left(\xi_{t}, \xi_{t}^{*}\right)=0.267$.

${ }^{37}$ The cross-country correlations are computed using output and the value added offshore deflated by the average price indexes in each economy, since the empirical price deflators are best represented by the average price index $\widetilde{P}_{t}$ rather than the welfare-based price index $P_{t}$ (see Ghironi and Melitz, 2007). For instance, output in the North is deflated as $Y_{R, t}=P_{t} Y_{t} / \widetilde{P}_{t}=\left(N_{D, t}+N_{V, t}+N_{H, t}^{*}\right)^{\frac{1}{1-\theta}} Y_{t}$, using the decomposition of the price index into its (i) variety and (ii) average price components: $P_{t}=\left(N_{D, t}+N_{V, t}+N_{H, t}^{*}\right)^{\frac{1}{1-\theta}} \widetilde{P}_{t}$.
} 
$\operatorname{Corr}\left(Y_{R}, V A_{R}\right)>\operatorname{Corr}\left(Y_{R}, Y_{R}^{*}\right)$. This result is consistent with the empirical correlations presented in column 1 (and discussed in Section 5.1), which show that the maquiladora value added comoves more closely with the U.S. manufacturing output than does Mexico's total manufacturing output. Notably, the ranking of the two correlations is preserved when the correlation of shocks and the productivity spillovers are shut down in the bivariate productivity process (see Table D.7 of the Technical Appendix). More, the correlation between output in the North and the number of offshoring plans (the extensive margin of offshoring) is positive like in the data, $\operatorname{Corr}\left(Y_{R}, N_{V}\right)>0 . .^{38}$

Intuitively, in the model, the value added offshore (which is part of the South output) is procyclical and strongly correlated with output in the North, as a result of the extensive and intensive margin dynamics of offshoring described in Section 5.2. However, an increase in aggregate productivity in the North weakens the economic activity elsewhere in the South, given that firm profits and firm entry are dampened in the relatively less productive economy, which partially offsets the positive effect from offshoring on output comovement. ${ }^{39}$ In addition, offshoring reduces the profits of Southern exporters, as it transfers some of the upward wage pressure from the North to the South. As a result, the correlation between total output in the North and the South is lower than the correlation between output in the North and the value added offshore.

The ranking of correlations is also robust for the alternative models with international bond trading, elastic labor supply and physical capital, also shown in Table 3. With bond trading, the correlations of the value added offshore and the number of offshoring firms with output

\footnotetext{
${ }^{38}$ Note that the positive spillover from the North to the South productivity dampens the initial depreciation of the terms of labor, which in turn dampens the initial decline in the extensive margin.

${ }^{39}$ See the impulse responses in Figures D.5 and D.6, in which the magnitude of shocks and persistence of productivity are calibrated for the United States and Mexico, but the correlation of shocks and productivity spillovers are set to zero.
} 
in the North are larger than in financial autarky: Since a positive shock to productivity in the North has a more muted initial effect on the terms of labor, the the number of offshoring firms and the value added offshore exhibit positive and larger initial responses than in financial autarky, as discussed earlier (see Figure 5). Also, with elastic labor supply, the cross-country correlation of output is smaller than in the baseline model, given the divergent responses of labor supply and labor income across countries.

\subsubsection{Cross-correlations}

This section analyzes the model cross-correlations for each of the following four indicators with lags and leads of output in the North: (i) the total output in the South; (ii) the offshoring value added in the South; (iii) the number of Northern firms that produce offshore, as an indicator for the extensive margin of offshoring; and (iv) the value added per offshoring firm, as an indicator for the intensive margin. For each indicator, Figure 8 plots the cross-correlations implied by the model, and compares them to their empirical counterparts.

To compute the model cross-correlations, I simulate series of the productivity shocks $\xi_{t}$ and $\xi_{t}^{*}$ for a length of 68 periods (which coincides with the length of the maquiladora data series discussed in Section 5.1), using the baseline calibration of the bivariate productivity process for the United States and Mexico. Then the series of simulated shocks are fed into the model, and the cross-correlations of the HP-filtered simulated series are computed for model variables. This procedure is repeated 5,000 times, and the average moments across simulations are reported in Figure $8 .{ }^{40}$

First, the model cross-correlations of total output in the South with output in the North

\footnotetext{
${ }^{40}$ The contemporaneous correlations based on model simulations should be very close to the theoretical correlations reported in Table 3 , but not necesarely identical.
} 
(panel 1), and the cross-correlations of the offshoring value added with output in the North (panel 2) are tent-shaped, with the positive peak happening contemporaneously like in the data. More, as already discussed, the offshoring value added comoves more closely with output in the North than does the total Southern output.

Second, the model is successful in capturing the delayed adjustment in the extensive margin, as it generates inter-temporal dynamics for the number of offshoring firms that are consistent with those from the data. In panel 3, the cross-correlations of the number of offshoring firms with lags and leads of the Northern output are S-shaped, rather than tent-shaped like in panels 1 and 2. In general, they peak for the Northern output lagged by about three quarters, like in the data. The result arises from the property that, following a productivity increase in the North, domestic firm entry causes the terms of labor to appreciate gradually, which in turn leads to a gradual increase in the number of offshoring firms. The delayed response of the extensive margin is stronger with elastic labor supply, due to the greater appreciation of the terms of labor discussed before, but somewhat weaker with physical capital, due to the substitution between investment and firm entry.

Third, regarding the intensive margin (panel 4), the correlations between the value added per offshoring firm and lagged Northern output are negative as in the data, both in the baseline model, as well as with elastic labor supply and physical capital. The result arises from the property that, in response to a positive shock to productivity in the North, the initial increase in value added per offshoring firm is followed by a decline below its steady-state level, which explains the negative correlations between the intensive margin and lagged output in the North. 


\subsection{Offshoring and Output Comovement}

This section examines the relationship between offshoring and output comovement generated by the model with heterogeneous firms, and compares it to the empirical evidence from BKT, who document the positive relation between the share of offshoring-related trade in bilateral trade and output comovement across countries. Using annual data on manufacturing value added and trade for the United States and 34 trading partners, BKT estimate equation (23) in a crosssectional framework, in which the dependent variable is the correlation between manufacturing output in the United States and output in each of its trading partners over 1983-2005, while the explanatory variables are the offshoring intensity of bilateral trade (the first variable), and the reliance on exports to the United States for each trading partner (the second variable): ${ }^{41}$

$$
\text { Correlation }_{U S, j}=\alpha+\beta_{1}\left(\frac{\text { affilsales }_{j}}{m f t g E X P_{j}}\right)+\beta_{2}\left(\frac{m f t g E X P_{j}}{m f t g V A_{j}}\right)+\varepsilon_{j} .
$$

The estimation results in BKT indicate a positive link between the correlation of output and the share of offshoring in bilateral trade: $\beta_{1}=0.746$ is statistically significant at the 5 percent level, whereas $\beta_{2}=0.140$ is not statistically significant.

To analyze the implications of the model of offshoring with heterogeneous firms for output comovement, I use alternative calibrations for the fixed costs of offshoring and exporting to vary the steady-state share of offshoring in Southern exports, while holding the share of total exports in output fixed for both countries. ${ }^{42}$ For each alternative calibration, output correlations are

\footnotetext{
${ }^{41}$ See BKT for details. The offshoring intensity of bilateral trade is measured as the sales of U.S. foreign affiliates back to the United States expressed as a share of country $j$ 's total exports to the United States. The reliance on exports to the United States is measured as a share of country $j$ 's manufacturing output.

${ }^{42}$ To obtain this result, I vary $f_{V} \in[0.045,0.405], f_{H} \in[0.005,0.071]$ and $f_{H}^{*} \in[0.016,0.038]$, and select the calibrations that closely match the steady-state share of exports in output from the baseline calibration $(0.26 \pm 0.0015$ for the North, $0.44 \pm 0.0015$ for the South), while allowing for the share of offshoring-related trade in Southern exports to vary from about 0.45 to 0.70 .
} 
computed with the bivariate productivity process calibrated for the United States and Mexico. The results in Figure 9 show that larger shares of offshoring in Southern exports (on the horizontal axis) are associated with larger correlations of output (on the vertical axis), in line with the empirical evidence. The results hold both for the baseline model with financial autarky and with international bond trading (panel a), and also for the alternative models with endogenous labor supply and physical capital (panel c).

To quantify the model implications, the regression of output correlations (on the vertical axis in Figure 9) on a constant term and the share of offshoring in Southern exports (on the horizontal axis) generates the slope estimates $\beta=0.44$ for the baseline model with financial autarky, and $\beta=0.39$ for international bond trading. In each case, the slopes from the model are more than half of the empirical estimates from BKT. The slope is smaller for trade in bonds, since a greater prevalence of offshoring increases the profitability of Northern firms, which in turn enhances cross-border lending in response to an aggregate productivity increase in the North, and thus offsets some of the extra comovement from offshoring. The slope is somewhat less steep with elastic labor supply $(\beta=0.26)$; is steeper with physical capital $(\beta=0.71)$, when offshoring affects a larger share of aggregate income in the north (i.e. not only labor income, but also the return from capital).

The result also holds when, in the baseline model, the productivity shocks and persistence in the bivariate productivity process (22) are calibrated for the United States and Mexico as before, but with the shock correlations and productivity spillovers set to zero (panel b in Figure 9). As expected, the levels and the slopes of output correlations are somewhat lower than before ( $\beta=0.29$ under financial autarky and $\beta=0.12$ for international bond trading), but still positive. 
Note that, while the model of endogenous offshoring with heterogeneous firms is consistent with the empirical evidence in BKT, the comovement of output is generated by a mechanism that is different from BKT. As already discussed, the model in BKT abstracts from the extensive margin dynamics, and output comovement results from a relatively low elasticity of substitution between country-specific goods in the vertically-integrated sector. In contrast, in the model of offshoring with heterogeneous firms presented here, the the elasticity of substitution between home and offshore varieties is set at a relatively high level, and hence the intensive margin plays a smaller role. Instead, output comovement arises from the procyclical pattern of firm entry in the North, the procyclical appreciation of the terms of labor, and in turn the adjustment of the offshoring along both its extensive and intensive margins, as shown in Sections 5.2 and 5.3 above.

\section{Conclusion}

This paper examines the effect of offshoring motivated by lower production costs on the crosscountry transmission of business cycles, in a model with endogenous firm entry, heterogeneous firms, and endogenous offshoring. The model implications are consistent with the empirical pattern of offshoring undertaken by the U.S. multinational firms in Mexico. First, the model generates a procyclical pattern of offshoring, which arises from the gradual adjustment in offshoring along its extensive margin and the immediate adjustment along the intensive margin in response to shocks in the home economy, like in the data. Second, the offshoring sector comoves more closely with home output than does the total output of the foreign economy. Third, offshoring enhances the comovement of output between the economies involved. Impor- 
tantly, these results are closely related to the procyclical firm entry in the home economy, the procyclical appreciation of the terms of labor, and the extensive and intensive margin dynamics of offshoring.

The model of offshoring with heterogeneous firms built here is useful to study a number of issues related to the international mobility of production and labor. Thus, the framework is useful to analyze the effect of offshoring on employment dynamics in the home and foreign economies. In addition, offshoring has important implications for production costs, prices and the real exchange rates, and thus the model is useful to study the impact of offshoring on the Balassa-Sameulson effect. Nonetheless, the interaction between offshore production and labor migration across tradable and non-tradable sectors represents a topic with rich policy implications.

\section{References}

[1] Aguiar, Mark and Gita Gopinath. 2007. "Emerging Market Business Cycles: The Cycle Is the Trend." Journal of Political Economy, 155(1): 62-102.

[2] Alessandria, George and Horag Choi. 2007. "Do Sunk Costs of Exporting Matter for Net Export Dynamics?" Quarterly Journal of Economics, 122(1): 289-336.

[3] Anderson, James and Erik van Wincoop. 2004. "Trade Costs." Journal of Economic Literature, 42(3): 691-751.

[4] Arkolakis, Costas and Ananth Ramanarayanan. 2009. "Vertical Specialization and International Business Cycle Synchronization." Scandinavian Journal of Economics, 111(4): 655-680.

[5] Arseneau, David and Sylvain Leduc. 2011. "Threatening to Offshore in a Search Model of the Labor Market," Federal Reserve Board, mimeo.

[6] Bergin, Paul R.; Robert C. Feenstra; and Gordon H. Hanson. 2009. "Outsourcing and Volatility: Evidence from Mexico's Maquiladora Industry." American Economic Review, 99 (4): 1664-1671. 
[7] Bergin, Paul R.; Robert C. Feenstra; and Gordon H. Hanson. 2011. "Volatility due to Offshoring: Theory and Evidence." Journal of International Economics, 85(2011): 163173.

[8] Bernard, Andrew B.; Jonathan Eaton; J. Bradford Jensen; and Samuel Kortum. 2003. "Plants and Productivity in International Trade." American Economic Review, 93(4): 1268-1290.

[9] Bernard, Andrew B.; J. Bradford Jensen; Stephen Redding; and Peter K. Schott. 2007. "Firms in International Trade." Centre for Economic Performance Discussion Papers 0795.

[10] Burstein, Ariel; Christopher Kurz; and Linda Tesar. 2008. "International Trade, Production Sharing and the Transmission of Business Cycles." Journal of Monetary Economics, 55(4): 775-795.

[11] Contessi, Silvio. 2010. "How Does Multinational Production Change International Comovement?" Federal Reserve Bank of St. Louis, Working Paper 2010-041A.

[12] Economist, The. 2011. "Multinational manufacturers moving back to America: the dwindling allure of building factories offshore."

[13] Fattal Jaef, Roberto N. and Jose Ignacio Lopez. 2012. "Entry, Trade Costs and International Business Cycles." mimeo, International Monetary Fund and HEC Paris.

[14] Farhat, Daniel. 2009. "Endogenous Labor Supply, Heterogeneous Firms and International Business Cycles." mimeo, University of Otago.

[15] Ghironi, Fabio and Marc J. Melitz. 2005. "International Trade and Macroeconomic Dynamics with Heterogeneous Firms." Quarterly Journal of Economics, 120(3): 865-915.

[16] Greenwood, Jeremy; Zvi Hercowitz; and Gregory Huffman. 1988. "Investment, Capacity Utilization, and the Real Business Cycle," American Economic Review, 78(3): 402-417.

[17] Gruben, William C. 2001. "Was NAFTA behind Mexico's High Maquiladora Growth?" Economic and Financial Review, Third Quarter 2001, Federal Reserve Bank of Dallas.

[18] Hanson, Gordon H.; Raymond J. Mataloni; and Matthew J. Slaughter. 2005. "Vertical Production Networks in Multinational Firms." Review of Economics and Statistics, 87(4): 664-678.

[19] Hausman, Angela and Diana L. Haytko. 2003. "Cross-Border Supply Chain Relationships: Interpretive Research of Maquiladora Realized Strategies." Journal of Business and Industrial Marketing, 18(6/7): 545-563.

[20] Helpman, Elhanan. 2006. "Trade, FDI, and the Organization of Firms." Journal of Economic Literature, 44(3): 589-630.

[21] Helpman, Elhanan; Marc Melitz; and Stephen R. Yeaple. 2004. "Export versus FDI with Heterogeneous Firms." American Economic Review, 94(1): 300-316. 
[22] Helpman, Elhanan. 1984. "A Simple Theory of International Trade with Multinational Corporations." Journal of Political Economy, 92(3): 451-471.

[23] Instituto Nacional de Estadística y Geografía, Mexico (INEGI). 2008. Banco de Información Económica, Industria maquiladora de exportación, http://dgcnesyp.inegi.org.mx/cgiwin/bdieintsi.exe (accessed August 9, 2011).

[24] Kurz, Christopher J. 2006. "Outstanding Outsourcers: A Firm- and Plant-Level Analysis of Production Sharing." FEDs Working Paper No. 2006-04.

[25] Melitz, Marc. 2003. "The Impact of Trade on Intra-Industry Reallocations and Aggregate Industry Productivity." Econometrica, 71(6): 1695-1725.

[26] Ottaviano, Gianmarco; Giovanni Peri; and Gregory Wright. 2012. "Immigration, Offshoring and American Jobs," American Economic Review, forthcoming.

[27] Ramondo, Natalia and Andres Rodriguez-Clare. 2012. "Trade, Multinational Production, and the Gains from Openness," Journal of Political Economy, forthcoming.

[28] Silos, Pedro 2007. "Housing, Portfolio Choice and the Macroeconomy." Journal of Economic Dynamics and Control, 31: 2774-2801.

[29] World Bank. 2011. "Doing Business" (Starting a Business), http://www.doingbusiness.org/ (accessed August 8, 2011). 


\section{A Model Summary}

\section{A.1 Offshoring with Financial Autarky}

Table A.1

\begin{tabular}{|c|c|}
\hline Euler equation, bonds & $\begin{array}{l}C_{t}^{-\gamma}=\beta\left(1+r_{t+1}\right) E_{t}\left[C_{t+1}^{-\gamma}\right] \\
C_{t}^{*-\gamma}=\beta\left(1+r_{t+1}^{*}\right) E_{t}\left[C_{t+1}^{*-\gamma}\right]\end{array}$ \\
\hline Euler equation, stocks & $\begin{array}{l}\widetilde{v}_{t}=\beta(1-\delta) E_{t}\left[\left(\frac{C_{t+1}}{C_{t}}\right)^{-\gamma}\left(\widetilde{d}_{t+1}+\widetilde{v}_{t+1}\right)\right] \\
\widetilde{v}_{t}^{*}=\beta^{*}\left(1-\delta^{*}\right) E_{t}\left[\left(\frac{C_{t+1}^{*}}{C_{t}^{*}}\right)^{-\gamma}\left(\widetilde{d}_{t+1}^{*}+\widetilde{v}_{t+1}^{*}\right)\right]\end{array}$ \\
\hline Free entry & $\begin{aligned} \widetilde{v}_{t} & =\frac{f_{E} w_{t}}{Z_{t}} \\
\widetilde{v}_{t}^{*} & =\frac{f_{E}^{*} w_{t}^{*}}{Z_{t}^{*}}\end{aligned}$ \\
\hline Law of motion, total number of firms & $\begin{array}{l}N_{t+1}=(1-\delta)\left(N_{t}+N_{E, t}\right) \\
N_{D, t+1}^{*}=(1-\delta)\left(N_{D, t}^{*}+N_{E, t}^{*}\right)\end{array}$ \\
\hline Aggregate accounting & $\begin{array}{l}C_{t}+N_{E, t} \widetilde{v}_{t}=w_{t} L+N_{t} \widetilde{d}_{t} \\
C_{t}^{*}+N_{E, t}^{*} \widetilde{v}_{t}^{*}=w_{t}^{*} L^{*}+N_{D, t}^{*} \widetilde{d}_{t}^{*}\end{array}$ \\
\hline Consumption price index & $\begin{array}{l}1=N_{D, t}\left(\widetilde{\rho}_{D, t}\right)^{1-\theta}+N_{V, t}\left(\widetilde{\rho}_{V, t}\right)^{1-\theta}+N_{H, t}^{*}\left(\widetilde{\rho}_{H, t}^{*}\right)^{1-\theta} \\
1=N_{D, t}^{*}\left(\widetilde{\rho}_{D, t}^{*}\right)^{1-\theta}+N_{H, t}\left(\widetilde{\rho}_{H, t}\right)^{1-\theta}\end{array}$ \\
\hline Total profits & $\begin{array}{l}N_{t} \widetilde{d}_{t}=N_{D, t} \widetilde{d}_{D, t}+N_{V, t} \widetilde{d}_{V, t}+N_{H, t} \widetilde{d}_{H, t} \\
N_{D, t}^{*} \widetilde{d}_{t}^{*}=N_{D, t}^{*} \widetilde{d}_{D, t}^{*}+N_{H, t}^{*} \widetilde{d}_{H, t}^{*}\end{array}$ \\
\hline Total number of firms (North) & $N_{t}=N_{D, t}+N_{V, t}$ \\
\hline Offshoring profits link (North) & $\widetilde{d}_{V, t}=\frac{k}{k-(\theta-1)}\left(\frac{z_{V, t}}{\widetilde{z}_{D, t}}\right)^{\theta-1} \widetilde{d}_{D, t}+\frac{\theta-1}{k-(\theta-1)} f_{V} \frac{w_{t}^{*} Q_{t}}{Z_{t}^{*}}$ \\
\hline Export profits link & $\begin{aligned} \widetilde{d}_{H, t} & =\frac{\theta-1}{k-(\theta-1)} f_{H} \frac{w_{t}}{Z_{t}} \\
\widetilde{d}_{H, t}^{*} & =\frac{\theta-1}{k-(\theta-1)} f_{H}^{*} \frac{w_{t}^{*}}{Z_{t}^{*}}\end{aligned}$ \\
\hline $\begin{array}{l}\text { Avrg. prod. of domestic producers (North) } \\
\text { Avrg. prod. of offshore producers (North) }\end{array}$ & $\begin{array}{l}\widetilde{z}_{D, t}=\nu z_{\min } z_{V, t}\left[\frac{z_{V, t}^{k-(\theta-1)}-z_{\min }^{k-(\theta-1)}}{z_{V, t}^{k}-z_{\min }^{k}}\right]^{\frac{1}{\theta-1}} \\
\widetilde{z}_{V, t}=\nu z_{\min }\left(\frac{N_{t}}{N_{V, t}}\right)^{1 / k}\end{array}$ \\
\hline Avrg. productivity of exporters & $\begin{array}{l}\widetilde{z}_{H, t}=\nu z_{\min }\left(\frac{N_{t}}{N_{H, t}}\right)^{1 / k} \\
\widetilde{z}_{H, t}^{*}=\nu z_{\min }^{*}\left(\frac{N_{D, t}^{*}}{N_{H, t}^{*}}\right)^{1 / k}\end{array}$ \\
\hline Balanced trade & $\begin{array}{l}N_{H, t}\left(\widetilde{\rho}_{H, t}\right)^{1-\theta} C_{t}^{*} Q_{t}+N_{V, t} \widetilde{d}_{V, t}= \\
=N_{V, t}\left(\widetilde{\rho}_{V, t}\right)^{1-\theta} C_{t}+N_{H, t}^{*}\left(\widetilde{\rho}_{H, t}^{*}\right)^{1-\theta} C_{t}\end{array}$ \\
\hline
\end{tabular}




\section{A.2 Offshoring with International Bonds}

In the model version with financial integration, international asset markets are incomplete, as the representative household in each economy holds risk-free, country-specific bonds from both the North and the South. Each type of bonds provides a real return denominated in units of the issuing country's consumption basket. Quadratic costs of adjustment for bond holdings ensure stationarity for the net foreign assets in the presence of temporary shocks.

The representative household in the North maximizes inter-temporal utility subject to:

$$
\begin{aligned}
& \left(\widetilde{d}_{t}+\widetilde{v}_{t}\right) N_{t} x_{t}+w_{t} L+\left(1+r_{t}\right) B_{h, t}+\left(1+r_{t}^{*}\right) Q_{t} B_{f, t}+T_{t} \\
& \geqslant C_{t}+\widetilde{v}_{t}\left(N_{t}+N_{E, t}\right) x_{t+1}+B_{h, t+1}+\frac{\pi}{2}\left(B_{h, t+1}\right)^{2}+Q_{t} B_{f, t+1}+\frac{\pi}{2} Q_{t}\left(B_{f, t+1}\right)^{2},
\end{aligned}
$$

where $r_{t}$ and $r_{t}^{*}$ are the rates of return of the North and South-specific bonds; $\left(1+r_{t}\right) B_{h, t}$ and $\left(1+r_{t}^{*}\right) Q_{t} B_{f, t}$ denote the principal and interest income from each type of bonds; $\frac{\pi}{2}\left(B_{h, t+1}\right)^{2}$

and $\frac{\pi}{2} Q_{t}\left(B_{f, t+1}\right)^{2}$ are the adjustment costs for each type of bond holdings; $T_{t}$ is the fee rebate. Setting $\pi=0.005$, the two Euler equations for bonds are added to the baseline model:

$$
\begin{aligned}
& 1+\pi B_{h, t+1}=\beta\left(1+r_{t+1}\right) E_{t}\left[\left(\frac{C_{t+1}}{C_{t}}\right)^{-\gamma}\right], \\
& 1+\pi B_{f, t+1}=\beta\left(1+r_{t+1}^{*}\right) E_{t}\left[\frac{Q_{t+1}}{Q_{t}}\left(\frac{C_{t+1}}{C_{t}}\right)^{-\gamma}\right] .
\end{aligned}
$$


For the Southern representative household, the Euler equations for bonds are:

$$
\begin{aligned}
& 1+\pi B_{h, t+1}^{*}=\beta^{*}\left(1+r_{t+1}\right) E_{t}\left[\frac{Q_{t}}{Q_{t+1}}\left(\frac{C_{t+1}^{*}}{C_{t}^{*}}\right)^{-\gamma}\right], \\
& 1+\pi B_{f, t+1}^{*}=\beta^{*}\left(1+r_{t+1}^{*}\right) E_{t}\left[\left(\frac{C_{t+1}^{*}}{C_{t}^{*}}\right)^{-\gamma}\right] .
\end{aligned}
$$

The market clearing conditions for bonds are:

$$
B_{h, t+1}+B_{h, t+1}^{*}=0 \text { and } B_{f, t+1}+B_{f, t+1}^{*}=0 .
$$

Thus, financial integration through trade in bonds adds four new variables $\left(B_{h, t}, B_{f, t}, B_{h, t}^{*}\right.$, $\left.B_{f, t}^{*}\right)$ and six new equations $(25,26,27,28$, and the two equations under 29) while removing the original two Euler equations from the baseline model with financial autarky. Also, the new expressions for aggregate accounting in the North and the South are:

$$
\begin{gathered}
C_{t}+N_{E, t} \widetilde{v}_{t}+B_{h, t+1}+Q_{t} B_{f, t+1}=w_{t} L+N_{t} \widetilde{d}_{t}+\left(1+r_{t}\right) B_{h, t}+\left(1+r_{t}^{*}\right) Q_{t} B_{f, t}, \\
C_{t}^{*}+N_{E, t}^{*} \widetilde{v}_{t}^{*}+Q_{t}^{-1} B_{h, t+1}^{*}+B_{f, t+1}^{*}=w_{t}^{*} L^{*}+N_{D, t}^{*} \widetilde{d}_{t}^{*}+\left(1+r_{t}\right) Q_{t}^{-1} B_{h, t}^{*}+\left(1+r_{t}^{*}\right) B_{f, t}^{*} .
\end{gathered}
$$

Finally, the balanced current account condition is replaced by the balance of international payments equation, which shows that the current account balance (trade balance plus repatriated profits plus investment income) equals the negative of the financial account balance (the change in bond holdings):

$$
T B_{t}+\underbrace{N_{V, t} \widetilde{d}_{V, t}}_{\text {Repatriated profits }}+\underbrace{r_{t} B_{h, t}+r_{t}^{*} Q_{t} B_{f, t}}_{\text {Income from bonds }}=\underbrace{\left(B_{h, t+1}-B_{h, t}\right)+Q_{t}\left(B_{f, t+1}-B_{f, t}\right)}_{\text {Change in bond holdings }}
$$




\section{A.3 Offshoring with Physical Capital}

Table A.3

Euler equation, bonds $\quad C_{t}^{-\gamma}=\beta\left(1+r_{t+1}\right) E_{t}\left[C_{t+1}^{-\gamma}\right]$

$C_{t}^{*-\gamma}=\beta\left(1+r_{t+1}^{*}\right) E_{t}\left[C_{t+1}^{*-\gamma}\right]$

Euler equation, stocks $\quad \widetilde{v}_{t}=\beta(1-\delta) E_{t}\left[\left(\frac{C_{t+1}}{C_{t}}\right)^{-\gamma}\left(\widetilde{d}_{t+1}+\widetilde{v}_{t+1}\right)\right]$

$\widetilde{v}_{t}^{*}=\beta^{*}\left(1-\delta^{*}\right) E_{t}\left[\left(\frac{C_{t+1}^{*}}{C_{t}^{*}}\right)^{-\gamma}\left({\widetilde{d_{t+1}^{*}}}^{*}+\widetilde{v}_{t+1}^{*}\right)\right]$.

Law of motion, capital $K_{t+1}=\left(1-\delta^{k}\right) K_{t}+I_{t}-\frac{\pi^{k}}{2} I_{t-1}\left(\frac{I_{t}}{I_{t-1}}-1\right)^{2}$

$K_{t+1}^{*}=\left(1-\delta^{k}\right) K_{t}^{*}+I_{t}^{*}-\frac{\pi^{k}}{2} I_{t-1}^{*}\left(\frac{I_{t}^{*}}{I_{t-1}^{*}}-1\right)^{2}$

F.O.C. capital

$\lambda_{t}=\beta E_{t}\left[C_{t+1}^{-\gamma} r_{t+1}^{k}\right]+\beta\left(1-\delta^{k}\right) E_{t}\left[\lambda_{t+1}\right]$

$\lambda_{t}^{*}=\beta E_{t}\left[C_{t+1}^{*-\gamma} r_{t+1}^{* k}\right]+\beta\left(1-\delta^{k}\right) E_{t}\left[\lambda_{t+1}^{*}\right]$

F.O.C. investment

$C_{t}^{-\gamma}=\lambda_{t}\left[1-\pi^{k}\left(\frac{I_{t}}{I_{t-1}}-1\right)\right]+\beta E_{t}\left[\lambda_{t+1} \frac{\pi^{k}}{2}\left(\left(\frac{I_{t}}{I_{t-1}}\right)^{2}-1\right)\right]$

$C_{t}^{*-\gamma}=\lambda_{t}^{*}\left[1-\pi^{k}\left(\frac{I_{t}^{*}}{I_{t-1}^{*}}-1\right)\right]+\beta E_{t}\left[\lambda_{t+1}^{*} \frac{\pi^{k}}{2}\left(\left(\frac{I_{t}^{*}}{I_{t-1}^{*}}\right)^{2}-1\right)\right]$

Capital market clearing $K_{t}=N_{D, t} \widetilde{k}_{D, t}+N_{H, t} \widetilde{k}_{H, t}+\left(N_{E, t} \frac{f_{E}}{Z_{t}}+N_{H, t} \frac{f_{H}}{Z_{t}}\right)\left[\frac{\alpha w_{t}}{(1-\alpha) r_{t}^{k}}\right]$

$K_{t}^{*}=N_{D, t}^{*} \widetilde{k}_{D, t}^{*}+N_{V, t} \widetilde{k}_{V, t}^{*}+N_{H, t}^{*} \widetilde{k}_{H, t}^{*}+\left(N_{E, t}^{*} \frac{f_{E}^{*}}{Z_{t}^{*}}+N_{V, t} \frac{f_{V}}{Z_{t}^{*}}+N_{H, t}^{*} \frac{f_{H}^{*}}{Z_{t}^{*}}\right)\left[\frac{\alpha w_{t}^{*}}{(1-\alpha) r_{t}^{k *}}\right]^{1-\alpha}$

Free entry

$\widetilde{v}_{t}=\frac{f_{E}}{Z_{t}}\left(\frac{w_{t}}{1-\alpha}\right)^{1-\alpha}\left(\frac{r_{t}^{k}}{\alpha}\right)^{\alpha}$ and $\widetilde{v}_{t}^{*}=\frac{f_{E}^{*}}{Z_{t}^{*}}\left(\frac{w_{t}^{*}}{1-\alpha}\right)^{1-\alpha}\left(\frac{r_{t}^{k *}}{\alpha}\right)^{\alpha}$

Law of motion, firms $\quad N_{t+1}=(1-\delta)\left(N_{t}+N_{E, t}\right)$ and $N_{D, t+1}^{*}=(1-\delta)\left(N_{D, t}^{*}+N_{E, t}^{*}\right)$

Aggregate accounting $\quad N_{E, t} \widetilde{v}_{t}+C_{t}+I_{t}=N_{t} \widetilde{d}_{t}+w_{t} L+r_{t}^{k} K_{t}$

$N_{E, t}^{*} \widetilde{v}_{t}^{*}+C_{t}^{*}+I_{t}^{*}=N_{D, t}^{*} \widetilde{d}_{t}^{*}+w_{t}^{*} L^{*}+r_{t}^{k *} K_{t}^{*}$

Cons. price index $\quad 1=N_{D, t}\left(\widetilde{\rho}_{D, t}\right)^{1-\theta}+N_{V, t}\left(\widetilde{\rho}_{V, t}\right)^{1-\theta}+N_{H, t}^{*}\left(\widetilde{\rho}_{H, t}^{*}\right)^{1-\theta}$

$1=N_{D, t}^{*}\left(\widetilde{\rho}_{D, t}^{*}\right)^{1-\theta}+N_{H, t}\left(\widetilde{\rho}_{H, t}\right)^{1-\theta}$

Total profits

$N_{t} \widetilde{d}_{t}=N_{D, t} \widetilde{d}_{D, t}+N_{V, t} \widetilde{d}_{V, t}+N_{H, t} \widetilde{d}_{H, t}$

$N_{D, t}^{*} \widetilde{d}_{t}^{*}=N_{D, t}^{*} \widetilde{d}_{D, t}^{*}+N_{H, t}^{*} \widetilde{d}_{H, t}^{*}$

No. of firms (North) $\quad N_{t}=N_{D, t}+N_{V, t}$

Offshoring profits link $\quad \widetilde{d}_{V, t}=\frac{k}{k-(\theta-1)}\left(\frac{z_{V, t}}{\widetilde{z}_{D, t}}\right)^{\theta-1} \widetilde{d}_{D, t}+\frac{\theta-1}{k-(\theta-1)} \frac{f_{V} Q_{t}}{Z_{t}^{*}}\left(\frac{w_{t}^{*}}{1-\alpha}\right)^{1-\alpha}\left(\frac{r_{t}^{* k}}{\alpha}\right)^{\alpha}$

Export profits link $\quad \widetilde{d}_{H, t}=\frac{\theta-1}{k-(\theta-1)} \frac{f_{H}}{Z_{t}}\left(\frac{w_{t}}{1-\alpha}\right)^{1-\alpha}\left(\frac{r_{t}^{k}}{\alpha}\right)^{\alpha}$ and $\widetilde{d}_{H, t}^{*}=\frac{\theta-1}{k-(\theta-1)} \frac{f_{H}}{Z_{t}^{*}}\left(\frac{w_{t}^{*}}{1-\alpha}\right)^{1-\alpha}\left(\frac{r_{t}^{* k}}{\alpha}\right)^{\alpha}$

Avrg. productivity $\quad \widetilde{z}_{D, t}=\nu z_{\min } z_{V, t}\left[\frac{z_{V, t}^{k-(\theta-1)}-z_{\min }^{k-(\theta-1)}}{z_{V, t}^{k}-z_{\min }^{k}}\right]^{\frac{1}{\theta-1}}$ (domestic firms)

Avrg. productivity $\quad \widetilde{z}_{V, t}=\nu z_{\min }\left(\frac{N_{t}}{N_{V, t}}\right)^{1 / k}$ (offshoring firms)

Avrg. productivity $\quad \widetilde{z}_{H, t}=\nu z_{\min }\left(\frac{N_{t}}{N_{H, t}}\right)^{1 / k}$ and $\widetilde{z}_{H, t}^{*}=\nu z_{\min }^{*}\left(\frac{N_{D, t}^{*}}{N_{H, t}^{*}}\right)^{1 / k}$ (exporters)

Balanced trade $\quad N_{H, t}\left(\widetilde{\rho}_{H, t}\right)^{1-\theta} C_{t}^{*} Q_{t} \frac{16}{46} N_{V, t} \widetilde{d}_{V, t}=N_{V, t}\left(\widetilde{\rho}_{V, t}\right)^{1-\theta} C_{t}+N_{H, t}^{*}\left(\widetilde{\rho}_{H, t}^{*}\right)^{1-\theta} C_{t}$ 
Table 1. Average prices and profits

\begin{tabular}{lccclll}
\hline \hline Firm & Origin & Production & Market & Average prices & Average profits \\
\hline 1. & North & North & North & $\widetilde{\rho}_{D, t}=\frac{\theta}{\theta-1} \frac{w_{t}}{Z_{t} \tilde{z}_{D, t}}$ & $\widetilde{d}_{D, t}=\frac{1}{\theta}\left(\widetilde{\rho}_{D, t}\right)^{1-\theta} C_{t}$ \\
2. & South & South & South & $\widetilde{\rho}_{D, t}^{*}=\frac{\theta}{\theta-1} \frac{w_{t}^{*}}{Z_{t}^{*} \widetilde{z}_{D, t}^{*}}$ & $\widetilde{d}_{D, t}^{*}=\frac{1}{\theta}\left(\widetilde{\rho}_{D, t}^{*}\right)^{1-\theta} C_{t}^{*}$ \\
\hline 3. & North & South & North & $\widetilde{\rho}_{V, t}=\frac{\theta}{\theta-1} \tau \frac{w_{t}^{*} Q_{t}}{Z_{t}^{*} \widetilde{z}_{V, t}}$ & $\widetilde{d}_{V, t}=\frac{1}{\theta}\left(\widetilde{\rho}_{V, t}\right)^{1-\theta} C_{t}-f_{V} \frac{w_{t}^{*} Q_{t}}{Z_{t}^{*}}$ \\
\hline 4. & North & North & South & $\widetilde{\rho}_{H, t}=\frac{\theta}{\theta-1} \tau^{*} \frac{w_{t} Q_{t}^{t}}{Z_{t} \widetilde{z}_{H, t}}$ & $\widetilde{d}_{H, t}=\frac{1}{\theta}\left(\widetilde{\rho}_{H, t}\right)^{1-\theta} C_{t}^{*} Q_{t}-f_{H} \frac{w_{t}}{Z_{t}}$ \\
5. & South & South & North & $\widetilde{\rho}_{H, t}^{*}=\frac{\theta}{\theta-1} \tau \frac{w_{t}^{*} Q_{t}}{Z_{t}^{*} \tilde{z}_{H, t}^{*}}$ & $\widetilde{d}_{H, t}^{*}=\frac{1}{\theta}\left(\widetilde{\rho}_{H, t}^{*}\right)^{1-\theta} C_{t} Q_{t}^{-1}-f_{H}^{*} \frac{w_{t}^{*}}{Z_{t}^{*}}$ \\
\hline \hline
\end{tabular}

Table 2. Calibration parameters and steady-state targets

\begin{tabular}{ll|lrr}
\hline \hline Calibration parameters: & & Steady-state targets: & Data & Model \\
\hline Pareto distribution coeff. & $k=4.2$ & Maquila. VA in Mex. manufacturing & $20 \%$ & $20 \%$ \\
Iceberg trade cost & $\tau=1.2$ & Maquila. share in Mexican exports & $55 \%$ & $61 \%$ \\
Fixed offshoring cost & $f_{V}=0.095$ & Maquila. share in manuf. employment & $25 \%$ & $20 \%$ \\
Fixed exporting cost, North & $f_{H}=0.040$ & & & \\
Fixed exporting cost, South & $f_{H}^{*}=0.025$ & & & \\
\hline \hline
\end{tabular}

Table 3. Cross-country contemporaneous correlations

\begin{tabular}{l|c|c|c|c|c}
\hline \hline & Data & Baseline & \multicolumn{3}{|c}{ Alternative models } \\
\hline Correlations: & & & Bonds & Elastic L & Capital \\
\hline US IP, Mexico IP & 0.58 & 0.33 & 0.32 & 0.13 & 0.34 \\
US IP, maquiladora value added & 0.69 & 0.75 & 0.98 & 0.60 & 0.81 \\
US IP, maquiladora plants & 0.33 & 0.23 & 0.94 & 0.15 & 0.32 \\
\hline \hline
\end{tabular}


Figure 1: The firm-specific productivity cutoff $z_{V, t}$.

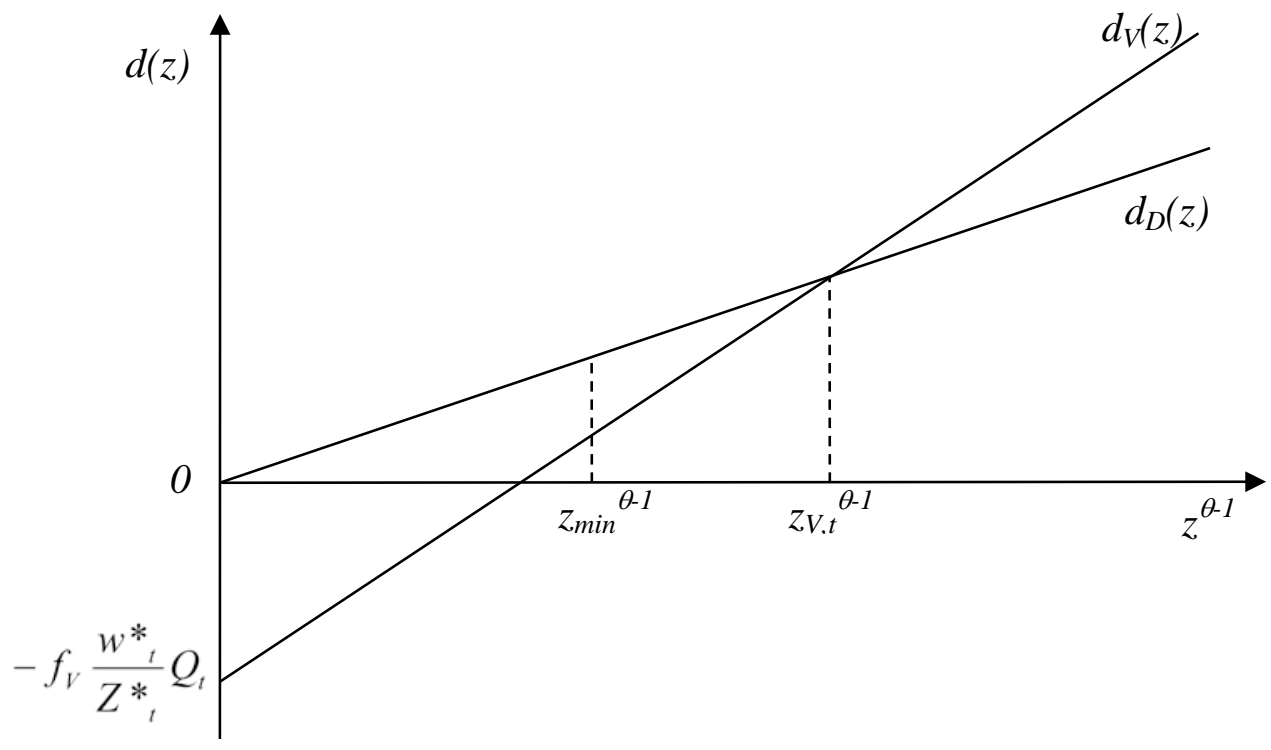

Figure 2: Average labor productivity for Northern firms that produce domestically $\left(\widetilde{z}_{D, t}\right)$ and offshore $\left(\widetilde{z}_{V, t}\right)$ for the North market.

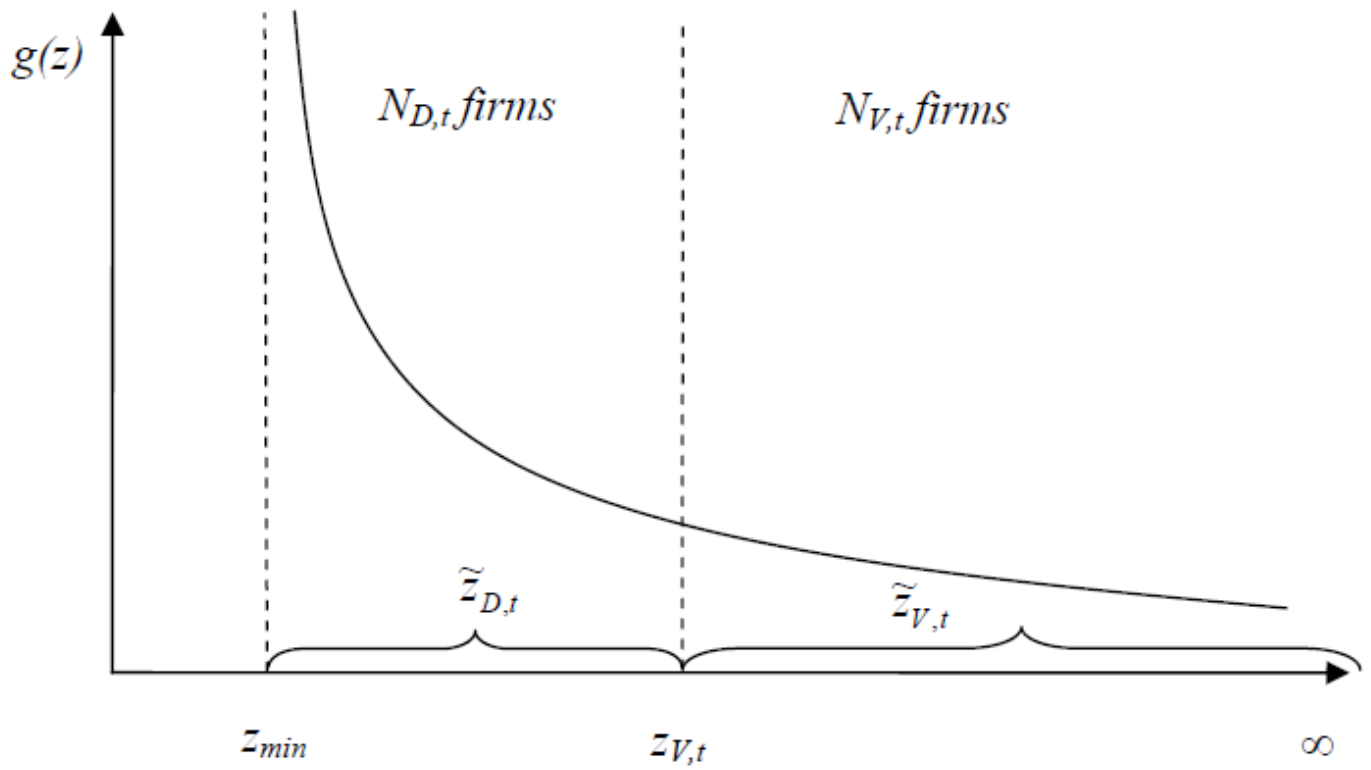


Figure 3: Business cycle dynamics in Mexico’s maquiladora sector.

1. Maquiladora Value Added and U.S. Manufacturing IP

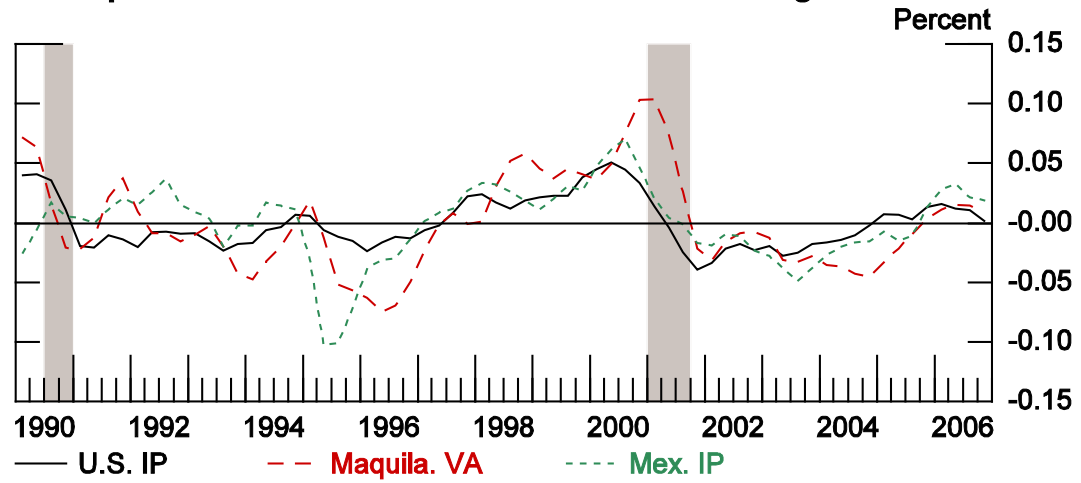

3. Maquiladora Plants and U.S. Manufacturing IP

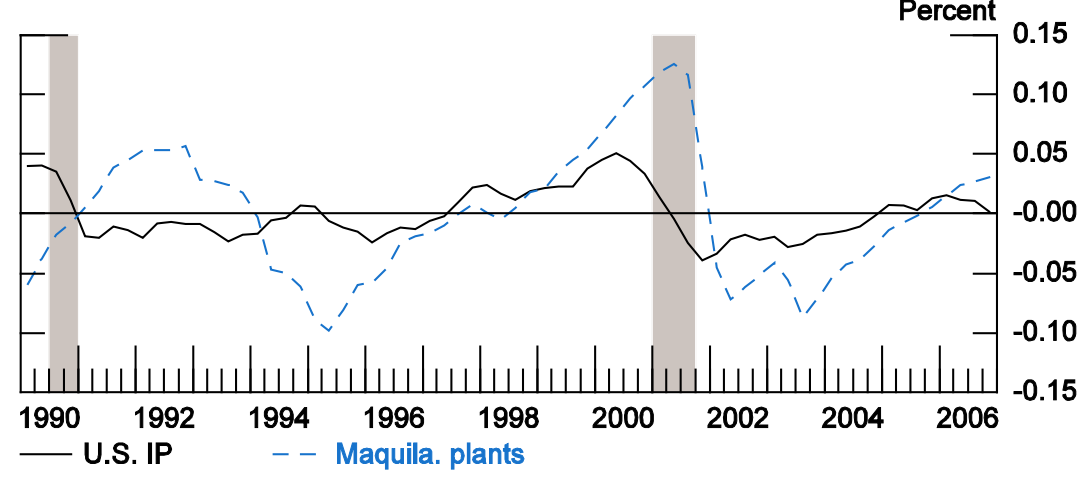

2. Cross Correlations with U.S. IP(t+j)

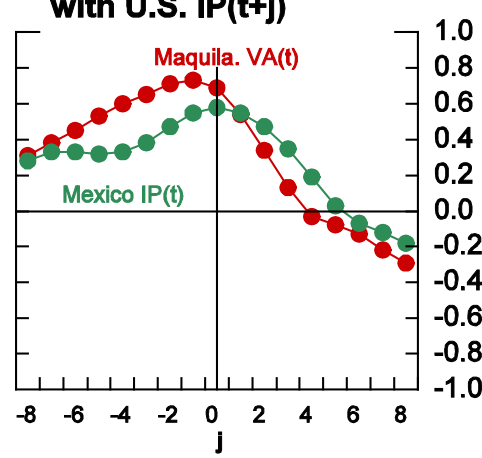

4. Cross Correlations with U.S. IP(t+j)

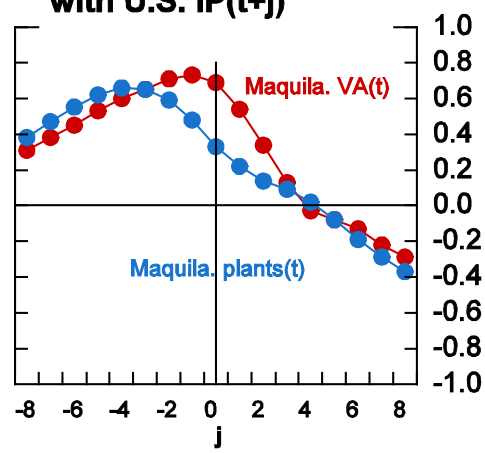

Data sources: Federal Reserve Board (for the U.S. manufacturing IP), Haver Analytics (for Mexico's manufacturing IP) and INEGI (for the maquiladora data).

Note: The data are seasonally adjusted, converted in natural logs, and expressed in deviations from a Hodrick-Prescott trend. See the Technical Appendix for details. 
Figure 4: Impulse responses to a one-percent shock to aggregate productivity in the North, with persistence $\rho=0.9$, baseline model with financial autarky.
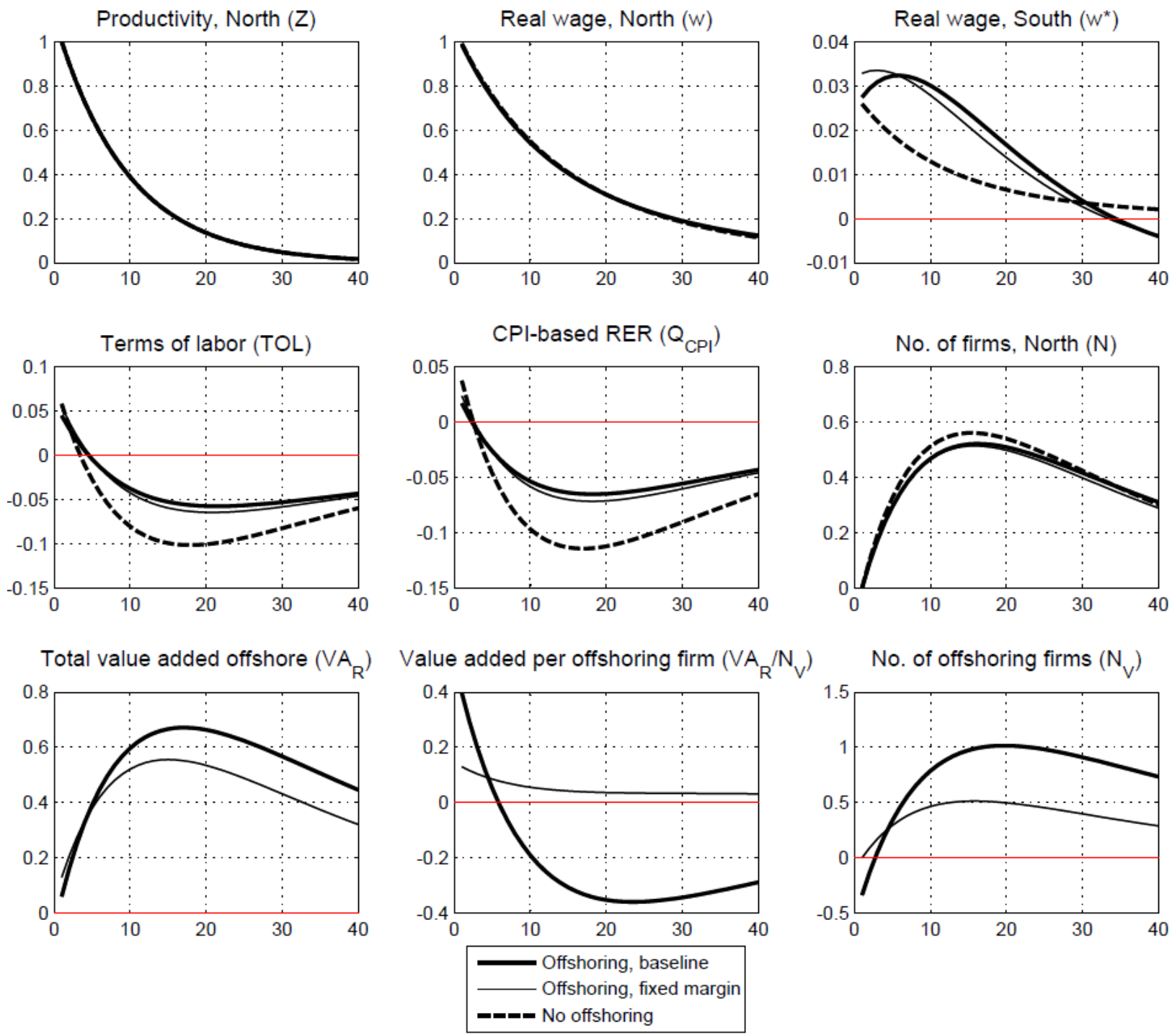

Note: the impulse responses correspond to: (1) the baseline model of offshoring (thick solid line); (2) alternative model with fixed productivity cutoff (thin solid line); (3) alternative model with no offshoring (dashed line). 
Figure 5: Impulse responses to a one-percent shock to aggregate productivity in the North, with persistence $\rho=0.9$, financial autarky vs. international bond trading.
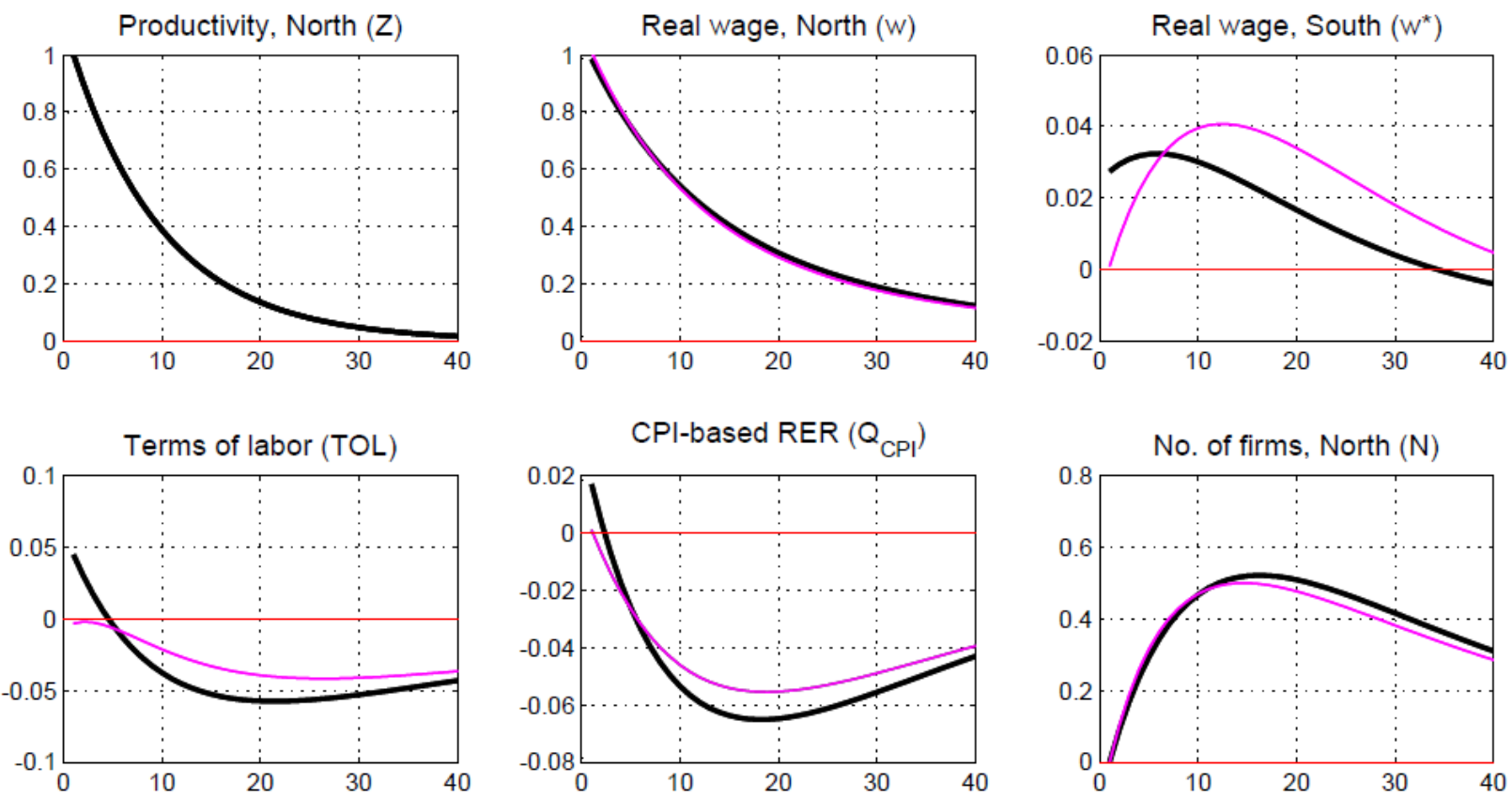

Total value added offshore $\left(V_{\mathrm{R}}\right)$

Value added per offshoring firm $\left(\mathrm{VA}_{\mathrm{R}} / \mathrm{N}_{\mathrm{V}}\right)$ No. of offshoring firms $\left(\mathrm{N}_{\mathrm{v}}\right)$
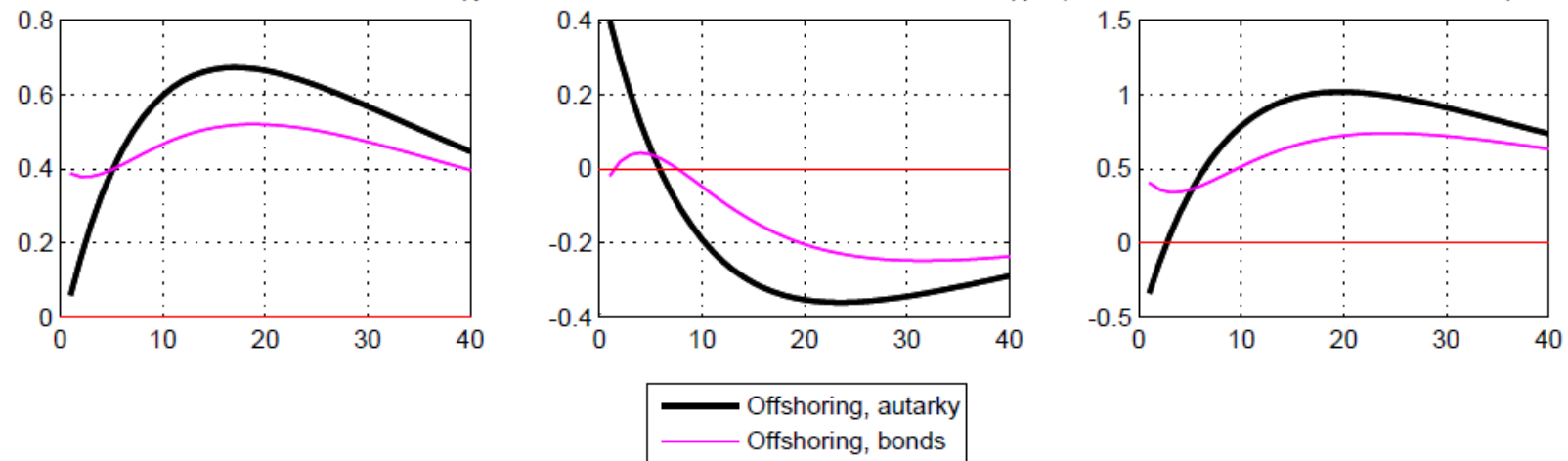
Figure 6: Impulse responses to a one-percent shock to aggregate productivity in the North, with persistence $\rho=0.9$, fixed vs. elastic labor supply.
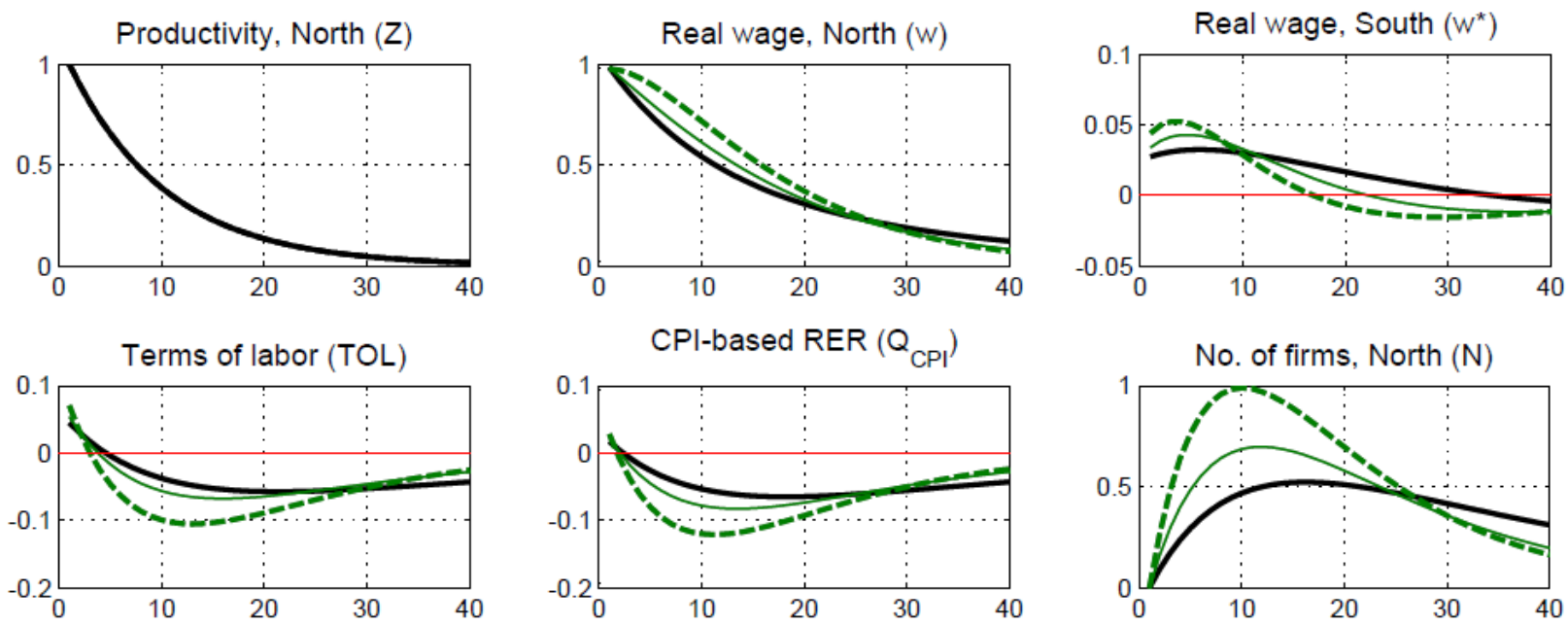

Total value added offshore $\left(V A_{R}\right)$

Value added per offshoring firm $\left(V A_{R} / N_{V}\right)$
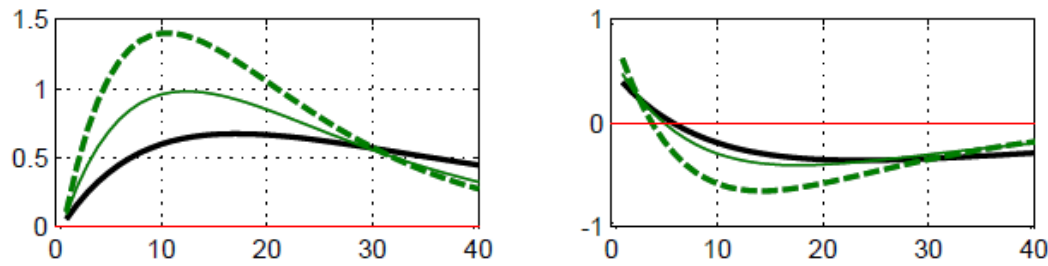

No. of offshoring firms $\left(\mathrm{N}_{\mathrm{v}}\right)$
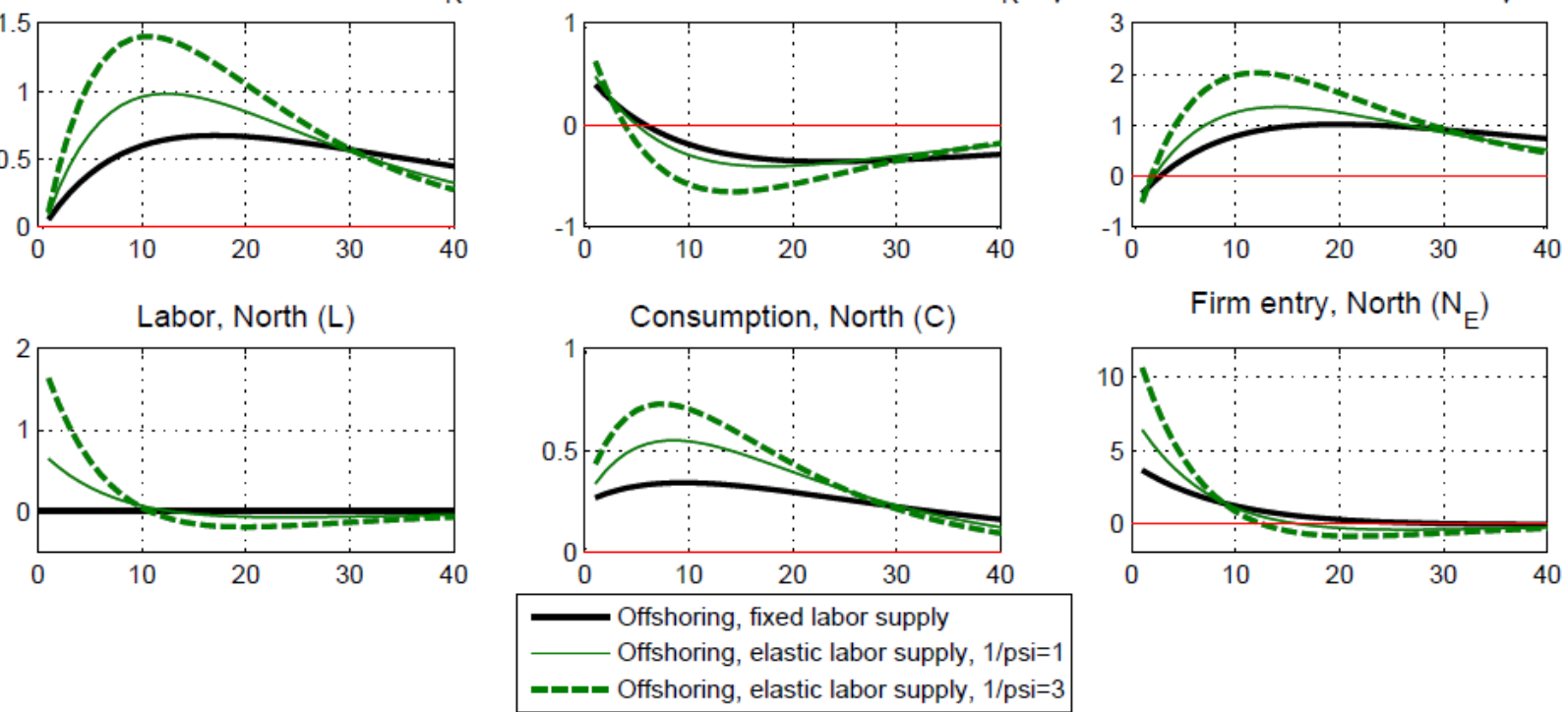

Firm entry, North $\left(\mathrm{N}_{\mathrm{E}}\right)$

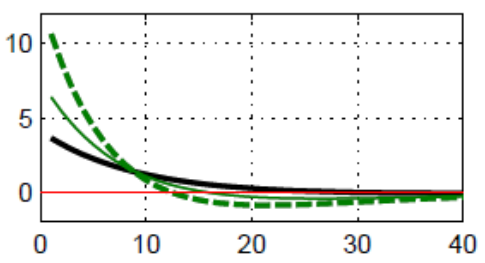


Figure 7: Impulse responses to a one-percent shock to aggregate productivity in the North, with persistence $\rho=0.9$, alternative model with physical capital.
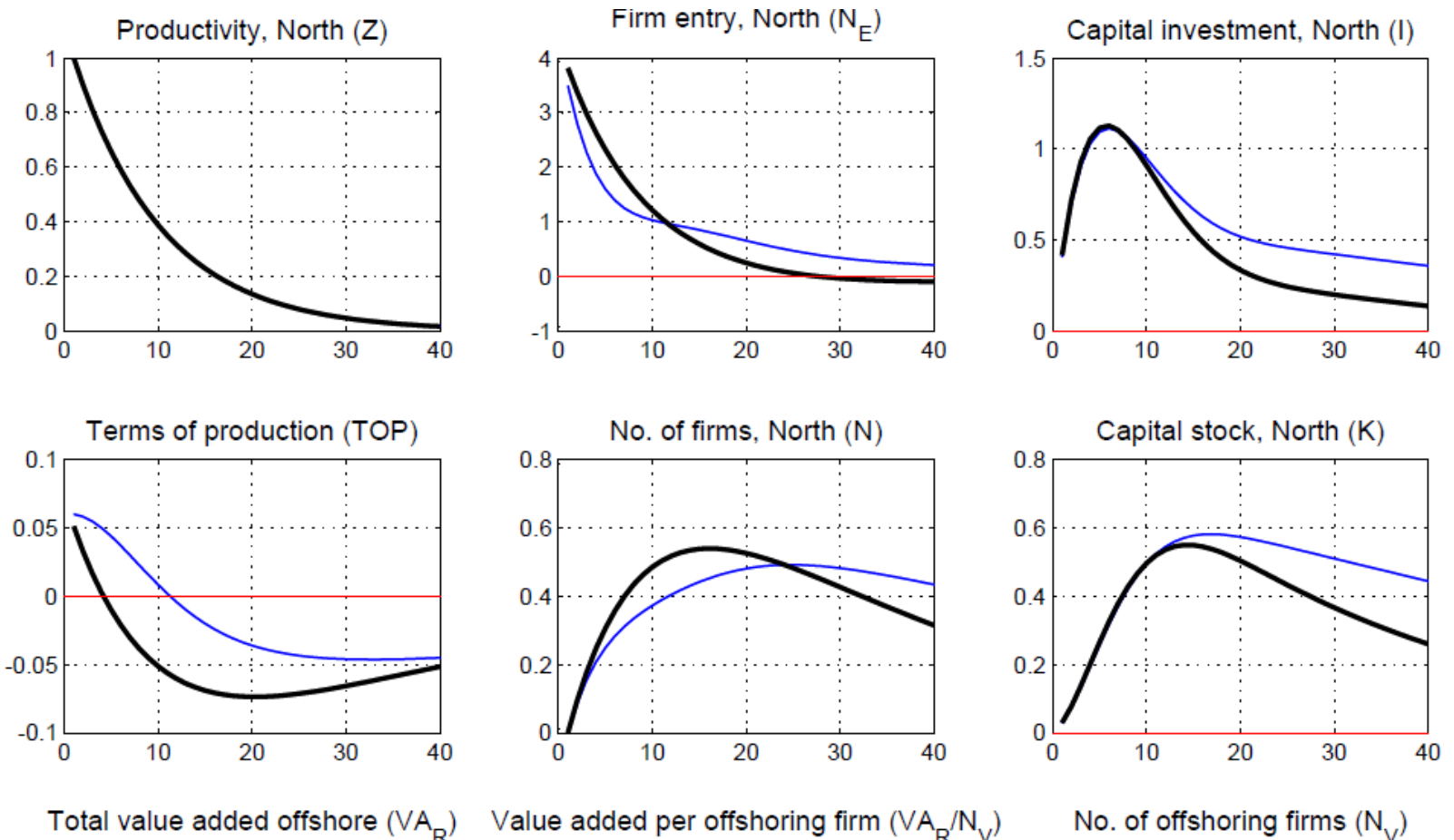

Value added per offshoring firm $\left(\mathrm{VA}_{\mathrm{R}} / \mathrm{N}_{\mathrm{V}}\right.$
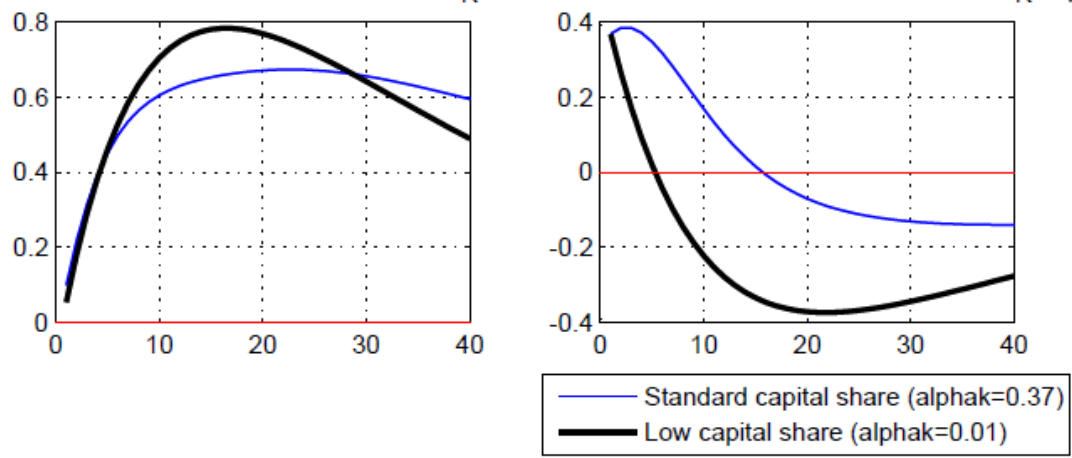

No. of offshoring firms $\left(\mathrm{N}_{\mathrm{v}}\right)$

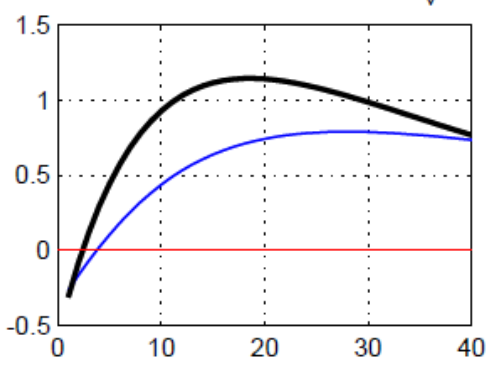


Figure 8: Cross-correlations, data vs. model.

1. Manufacturing cross-correlations: Mex IP (t) and US IP (t+j)

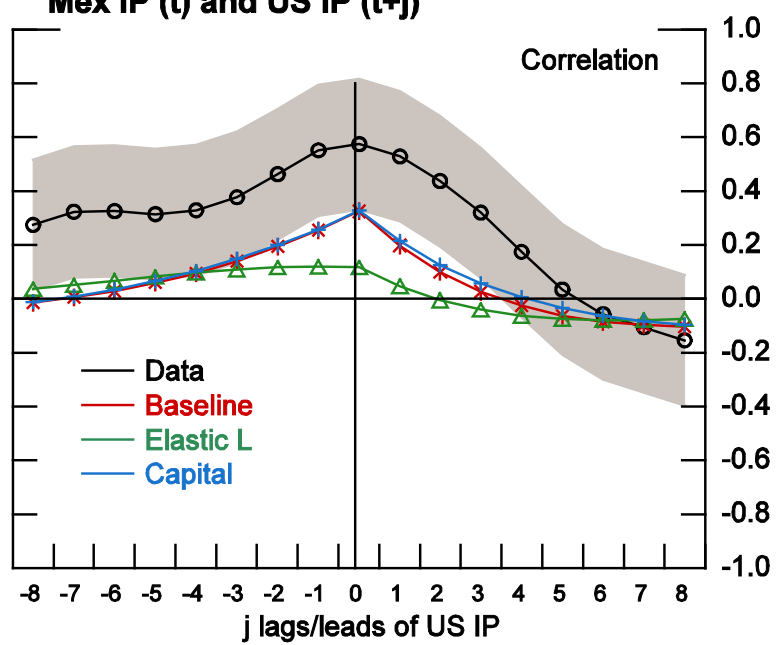

3. Extensive margin correlations: Number of plants $(t)$ and US IP $(t+j)$

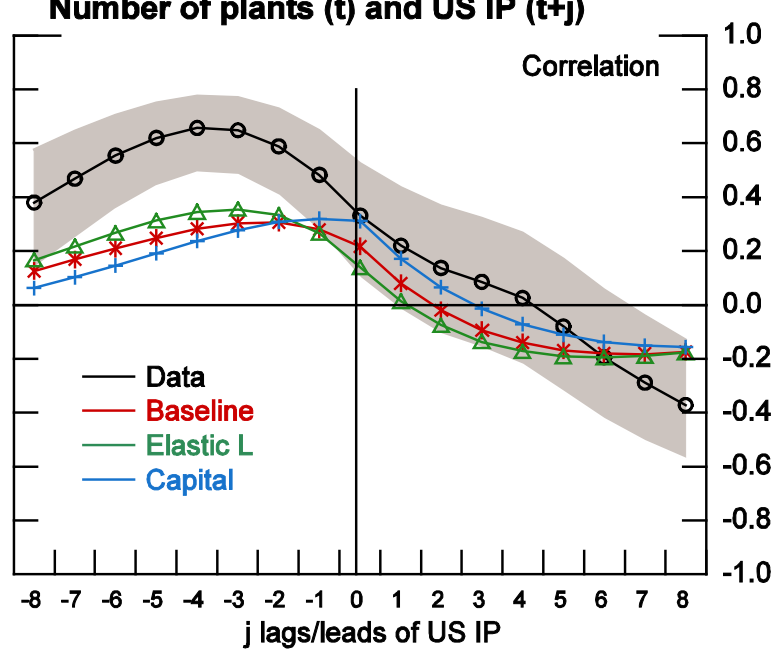

2. Offshoring cross-correlations:

Maquila value added $(t)$ and US IP $(t+j)$

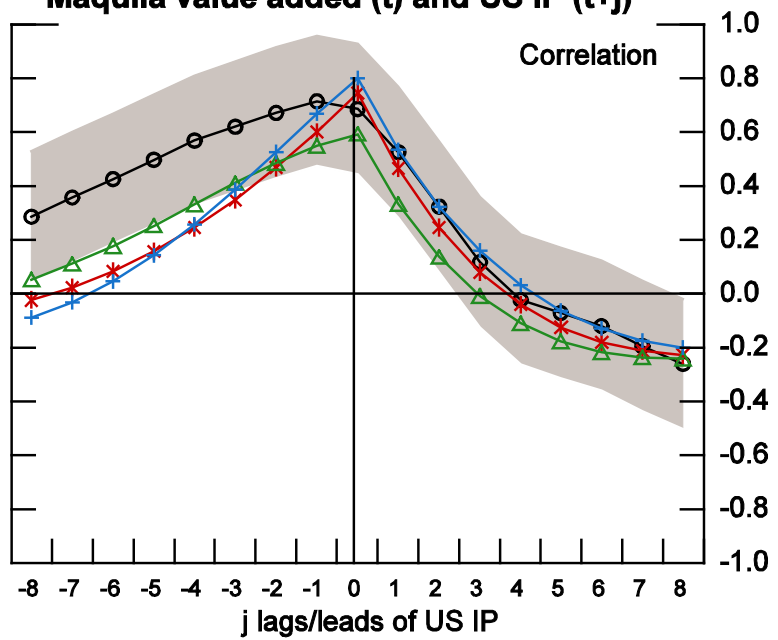

4. Intensive margin correlations: Value added per plant (t) and US IP (t+j)

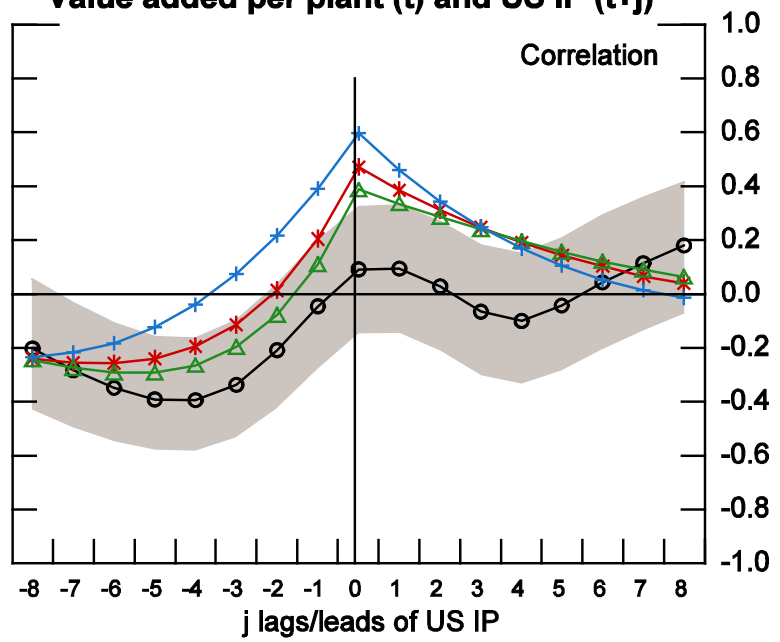

Note: the black line (circle marks) denotes the empirical cross-correlations, and the shaded area represents the 90 percent confidence bands. The red line (star marks) denotes the crosscorrelations from the baseline model with financial autarky; the green line (triangle marks) denotes the model cross-correlations with elastic labor supply; the blue line (cross marks) denotes the model cross-correlations with physical capital. For data sources, see the notes to Figure 3. 
Figure 9: Offshoring and output comovement.

(a) Baseline TFP calibration

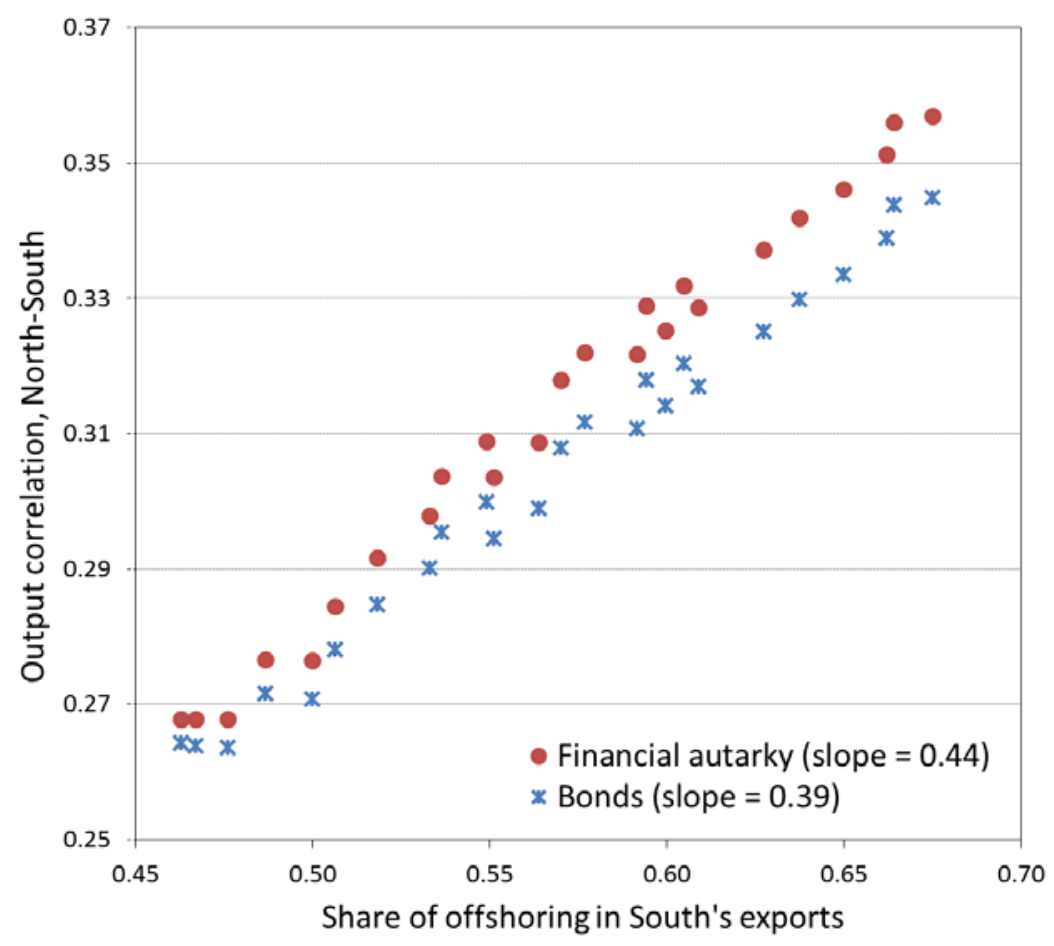

(b) Baseline TFP persistence and shocks, but zero spillovers and uncorrelated shocks

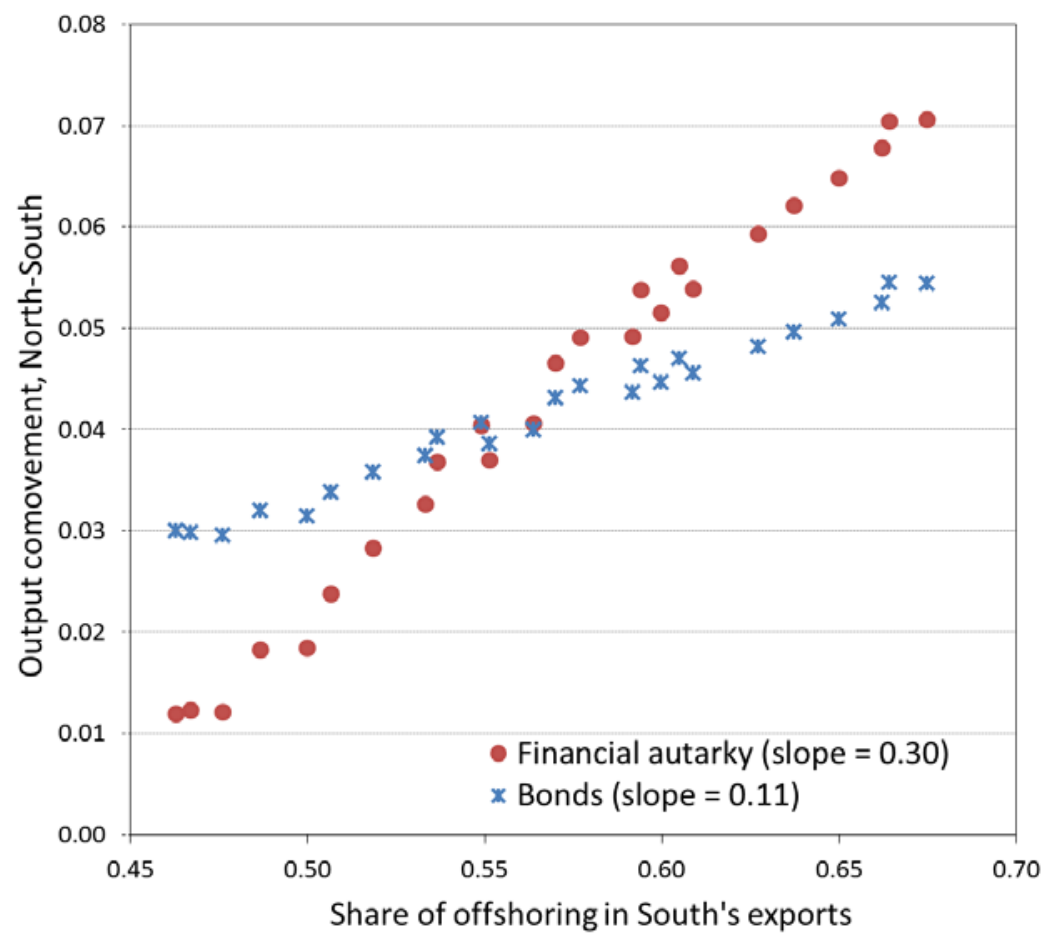


(c) Baseline TFP calibration, alternative models with elastic labor supply and capital

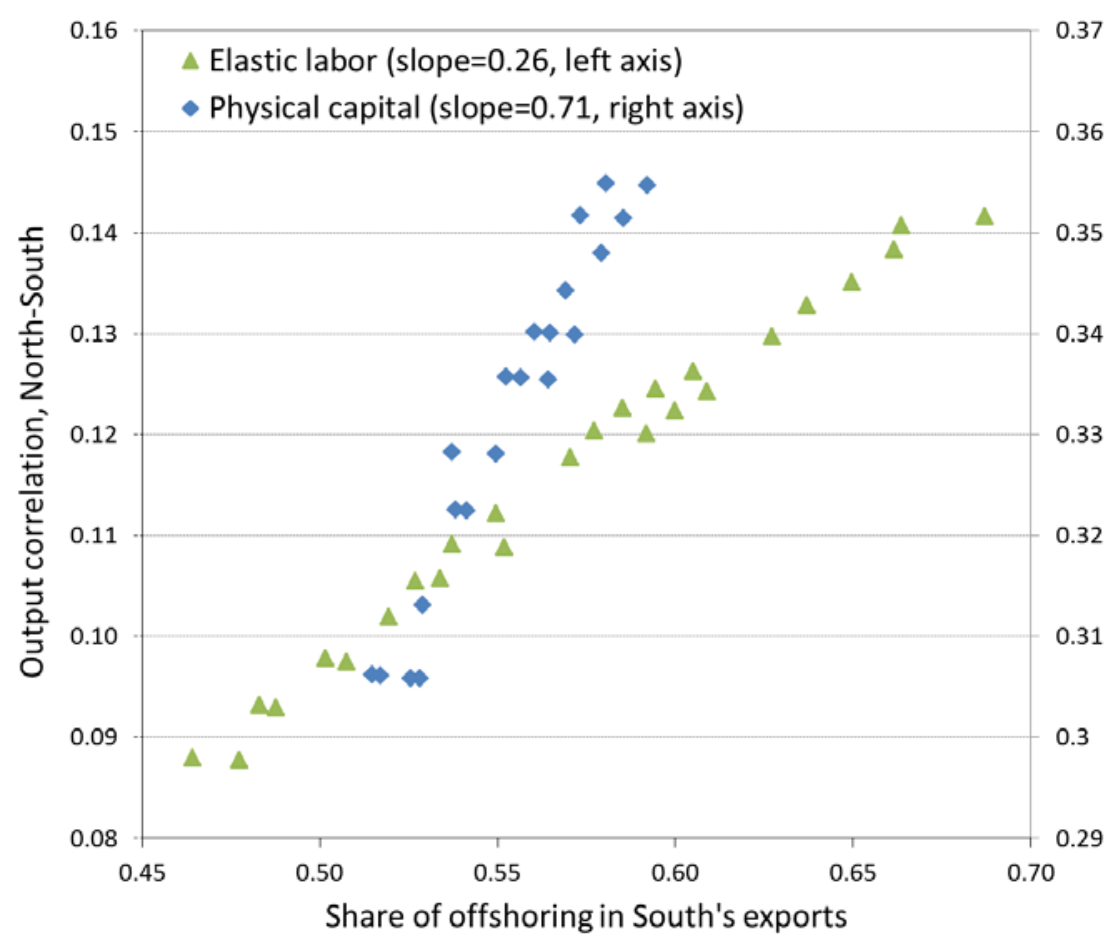

